\title{
Formulation and Evaluation of Fast Dissolving Buccal Film containing Vildagliptin
}

\author{
Savita V. Pol ${ }^{1 *}$, Jagtap R.S ${ }^{2}$, Doijad R.C ${ }^{3}$, Smita Takarkhede ${ }^{4}$, Jagtap S.R ${ }^{4}$ \\ 1.Department of Pharmaceutics, Ideal College of Pharmacy, Kalyan, Thane, India \\ 2.Department of Pharmaceutics, Annasaheb Dange college of B.Pharmacy, Ashta \\ 3.Department of Pharmaceutics, Shree Santkrupa College of pharmacy, Ghogoan \\ 4.Department of Pharmaceutics, Annasaheb Dange college of D.Pharmacy Ashta
}

\section{ABSTRACT}

The present study deals with the formulation of fast dissolving films of vildagliptin that is used for the treatment of Diabetes. The concept of fast dissolving drug delivery emerging from the desire to provide better patient compliance and avoid first pass metabolism. In the present research work, various trials were carried out using film forming agents such as HPMC, Maltodextrine, Polyethylene alcohol, to prepare an ideal film. Solvent casting method was used for the preparation of films. The prepared films were evaluated for weight uniformity, drug content, film thickness, folding endurance. The in vitro dissolution studies were carried out using ph-6.8 phosphate buffer. This approach increase therapeutic efficiency of pharmaceutical actives by avoiding hepatic first pass metabolism, deliver drug molecule in control manner, enhance absorption and improves patient compliance

Keywords: Fast dissolving buccal film, Vildagliptin, HPMC, Maltodextrine, poly-ethylene oxide' tween 80, aspartame Glycerin Solvent casting method, In vitro drug release, Ex-vivo drug diffusion studies, 


\section{INTRODUCTION}

Fast-dissolving drug-delivery systems were first developed in the late 1970s as an alternative to tablets, capsules, and syrups for paediatric and geriatric patients which rapidly disintegrate and dissolve in saliva and then easily swallowed without need of water. Fast dissolving oral films were first introduced in the market as breath fresheners and personal care products such as dental strips and soap strips. However, they are introduced in the United States and European pharmaceutical markets for therapeutic effect ${ }^{[1]}$. Fast dissolving oral films are most advance form of solid dosage form due to various reasons like flexibility, improved efficacy of API(Active Pharmaceutical Ingredient), dissolution and disintegration within 1 minute with the help of less amount of saliva as compared to dissolving tablet. Thin films have the potential to allow the development of sensitive drug targets that may otherwise not be possible in tablets or liquid formulations ${ }^{[2]}$.A film or strip can be defined as a dosage form that employs a water-dissolving polymer(generally a hydro colloid, which may be a bioadhesive polymer), which allows the dosage form to quickly hydrate, adhere, and dissolve when placed on the tongue or in the oral cavity(i.e. buccal, palatal, gingival, lingual, or sublingual) to provide rapid local or systemic drug delivery ${ }^{[3]}$. These oral strips may be flexible or brittle, opaque or transparent. ${ }^{[4]}$

Buccal mucosa is an attractive route for systemic delivery of drugs since it is relatively permeable with a rich blood supply. A drug can be easily applied and localized to the application site, and can be removed from there if necessary. Attempt has been made earlier to formulate various mucoadhesive buccal film. Formulation of fast dissolving buccal film involves the application of both aesthetic and performance characteristics such as strip forming polymers, plasticizers, active pharmaceutical ingredient, sweetening agents, saliva stimulating agent, flavoring agents, coloring agents, stabilizing and thickening agents ${ }^{[5]}$. From the regulatory perspectives, all excipients used in the formulation of oral drug strips should be approved for use in oral pharmaceutical dosage forms.

Oral ingestion is the most common and oldest route of administration which consists of tablets, capsules, etc. But this type of ingestion is not suitable for geriatric and pediatric patient suffering from the dysphasia, bedridden and non- compliant patients due to the fear of chocking. So, to overcome this disadvantage bioadhesive mucosal dosage forms have been introduced which includes adhesive tablets, gels, ointments, patches and then in 1970s polymeric films were introduced also known as oral thin films or fast dissolving films or mouth dissolving films or 
oro-dispersible films or quick disintegrating films and melt in mouth dosage form which was based on the technology of transdermal patches.

Diabetes mellitus is a disease characterize by hyperglycemia resulting from both insulin resistance and insulin deficiency which is secondary to pancreatic beta cell failure. Clinically, diabetes is dividing into two major components. Type 1 or insulin dependent diabetes mellitus (IDDM) it requires continuous exogenous insulin replacement therapy in addition to diet. Type 2 or non-insulin dependent diabetes mellitus (NIDDM) which usually occurs I $n$ mature individuals. The blood glucose levels abnormally raise is based on severity of the condition [6]. This approach increase therapeutic efficiency of pharmaceutical actives by avoiding hepatic first pass metabolism, deliver drug molecule in control manner, enhance absorption and improves patient compliance. ${ }^{[7]}$

Today, these are proven to be acceptable for OTC (Over the Counter) medications and are in the early to mid- development stages for prescription drug. Zulpenz is the first oral soluble disintegrating film approved by the FDA as a prescriptions medication ${ }^{[8]}$. These consists of thin oral films which get absorbed in the buccal cavity with the help of saliva, as hydrating agent without requirement of water and give their effect through pre-gastric absorption from mouth, pharynx and oesophagus as the saliva passes down into the stomachh [9].

\section{MATERIALS AND METHOD}

\section{Materials}

Vildagliptin was obtained as a gift sample from Cipla Ltd. HPMC was procured from Cipla. All other reagents used were of analytical grade. The films were prepared by solvent casting method.

\section{Methods $^{[10]}$}

The various methods are used to prepare fast dissolving buccal film. One or combination of the following process can be used to manufacture the mouth dissolving films:

1) Solvent casting method (It is used in this research work)

2) Semisolid casting

3) Hot melt extrusion

4) Solid dispersion extrusion

5) Rolling Method

\section{Preparation of drug loaded mouth dissolving film ${ }^{[11]}$ :}

The aqueous solution was prepared by dissolving polymers, plasticizers and the other components of the placebo formulations in distilled water and stirred with a magnetic stirrer. 
Then the active ingredient was added in the specific proportion to the obtained solution. The solution was stirred for $1 \mathrm{~h}$ and it was allowed to be kept aside for $2 \mathrm{~h}$ to remove air bubbles, and then $10 \mathrm{ml}$ of the solution was cast onto a glass petridish having a surface area of $71.76 \mathrm{~cm}^{2}$. The film solution was dried in a hot air oven at $45-50^{\circ} \mathrm{C}$. After drying, the films were removed with the help of a sharp blade and kept in a desiccator for $24 \mathrm{~h}$ before cutting it into small pieces, having an area of $4 \mathrm{~cm}^{2}$ for each film. Films with air bubbles, cuts, or imperfections were excluded from further study. Selected films were subjected to different evaluation parameters.

Table 1: Formulation of Vildagliptin mouth dissolving films by casting method

\begin{tabular}{llllllllll}
\hline Ingredients & \multicolumn{1}{c}{ Quantity for 18 films* } & \multicolumn{1}{c}{} \\
\cline { 2 - 10 } & F-1 & F-2 & F-3 & F-4 & F-5 & F-6 & F-7 & F-8 & F-9 \\
\hline HPMC E 15(mg) & 400 & 300 & 400 & 400 & 400 & 400 & 400 & 400 & 300 \\
Maltodextine(mg) & - & - & 105 & 125 & 125 & 125 & 125 & 125 & 125 \\
Vildagliptin(mg) & 50 & 50 & 50 & 50 & 50 & 50 & 50 & 50 & 50 \\
Polyethylene oxide & - & - & - & - & 10 & 5 & 2.5 & 1.5 & 10 \\
(mg) & & & & & & & & & \\
Citric acid(mg) & 30 & 30 & 30 & 30 & 30 & 30 & 30 & 30 & 30 \\
Aspartame(mg) & 15 & 15 & 15 & 15 & 15 & 15 & 15 & 15 & 15 \\
Glycerin(ml) & 0.1 & 0.1 & 0.1 & 0.1 & 0.1 & 0.1 & 0.1 & 0.1 & 0.1 \\
Tween 80(ml) & 0.04 & 0.04 & 0.04 & 0.04 & 0.04 & 0.04 & 0.04 & 0.04 & 0.04 \\
Ethanol & 7 & 7 & 7 & 7 & 7 & 7 & 7 & 7 & 7 \\
Water (q.s.) & 10 & 10 & 10 & 10 & 10 & 10 & 10 & 10 & 10 \\
\hline *size 4 cm & & & & & & & & & \\
PLAN OF WORK & & & & & & & & &
\end{tabular}

The proposed research work will be conducted in laboratory and the various steps that to be planned as follows:

1) Literature Review

2) Selection of Drug \& Excipients.

3) Pprocurement of Drug \& Excipients

4) Experimental work

1. Characterization of drug

a) Melting Point Determination

b) HPLC

c) IR spectroscopy

d) DSC study

2. Drug- excipients compatibility study by FTIR

5) Preparation of Vildagliptin mouth dissolving films with use of

a) Different film formers 
6)
a) Weight variation
b) Thickness
c) Tensile strength
d) Percentage Elongation
e) Folding endurance
f) Disintegration time
g) Content uniformity
h) In-vitro dissolution study
i) Ex-vivo drug diffusion studies

Characterization of mouth dissolving film

To carry out stability studies of the optimized

\section{formulation}

\section{EXPERIMENTAL INVESTIGATION}

\section{Procurement of Drug and Excipients:}

The drug, excipients, chemicals or reagents and equipment used for various experiments are enlisted as follows:

\section{Drug: VILDAGLIPTIN}

Excipients: HPMC E-15, Poly Ethylene Oxide, Maltodextine.

\section{Other chemicals:}

Glycerine, aspartame, Tween 80, citric acid, ethanol water. All the excipients used were of analytical grade.

Table 2: Active ingredients, excipients and their sources

\begin{tabular}{lll}
\hline Sr.No & Drug / Excipients & Source \\
\hline 1 & Vildagliptin & Cipla Ltd. \\
2 & Hydroxy propyl methyl cellulose $(15 \mathrm{cps})$ & Cipla Ltd. \\
3 & PolyEthelene oxide & Cipla Ltd. \\
4 & Maltodextrin & Cipla Ltd. \\
5 & Aspartame & Cipla Ltd. \\
6 & Tween -80 & Cipla Ltd. \\
7 & Ethanol & Cipla Ltd. \\
8 & Glyecerine & Cipla Ltd. \\
\hline
\end{tabular}

\section{Instruments and Equipments:}

Table 3: Equipment/Instrument used

\begin{tabular}{lll}
\hline Sr. No & Name of the equipment / instrument & Model \\
\hline 1 & High Precision Balance & Wensar \\
\hline
\end{tabular}




\begin{tabular}{lll}
\hline 2 & HPLC & Shimadzu LC 20 \\
3 & FTIR Spectrophotometer & Jasco-4100,Japan \\
4 & Programmable Melting Point Apparatus & Chemiline \\
5 & Magnetic Stirrer & Remi \\
6 & Dissolution Apparatus & Lab India \\
7 & Vernire caliper & Mitutoyo \\
8 & Hot air oven & Chemiline \\
9 & pH meter & Rolex India \\
\hline
\end{tabular}

\section{Preformulation study ${ }^{[12]}$ :}

Preformulation testing is the first step in rational development of dosage forms of a drug substance. Preformulation study is the process of optimizing the delivery of drug through determination of physicochemical properties of the new compound that could affect drug performance and development of an efficacious, stable and safe dosage form. It gives the information needed to define the nature of the drug substance and provide a framework for the drug combination with pharmaceutical excipients in the dosage form. Hence, preformulation studies were performed for the obtained sample of drug for identification and compatibility studies

\section{Characterization of Drug}

\section{A. Organoleptic properties:}

Vildagliptin powder was examined for appearance colour, odour and test.

\section{B. Solubility analysis:}

Preformulation solubility analysis was done, which include selection of suitable solvent to dissolve drug and also to test its solubility in diffusion medium, which was to be used.

\section{Melting point determination:}

The melting point of vildagliptinwas determined by melting point apparatus (Chemiline). The melting point was determined by introducing small amount of substance in the capillary attached to apparatus. The drug sample was tested in temperature range $30^{\circ} \mathrm{C}-300^{\circ} \mathrm{C}$ and point at which drug melts was noted.

\section{Determination of $\mathbf{p H}$ :}

The $\mathrm{pH}$ of Vildagliptinin distilled water checked by using digital $\mathrm{pH}$ meter and the reading was noted.

\section{E. HPLC ${ }^{[13]}$}

\section{a) Instrumentation}




\section{Instrument}

HPLC System

- Pump:

- Detector:

- Data processor

- Column:

Weighing Balance:

Digital pH Meter:

Ultrasonicator:

\section{Specifications}

Shimadzu HPLC system

LC-20 AT VP solvent delivery system

SPD M-10AVP photo diode array detector

LC solution

Princeton SPHERE C18 column (250 mm x $4.6 \mathrm{~mm}$ x $5 \mu$ )

SHIMADZU AUX - 120

Systronics $\mu \mathrm{pH}$ System 362

ENERTECH Electronics Pvt. Ltd.

\section{b) Chromatographic conditions:}

Princeton SPHERE C18 column $(250 \mathrm{~mm}$ x $4.6 \mathrm{~mm}$ x $5 \mu)$ was used as stationary phase. Acetonitrile: $10 \mathrm{mM}$ Phosphate buffer ( Di Potassium Hydrogen Phosphate, pH - 4.5 (adjusted with Ortho Phosphoric Acid)) in the ratio of 70:30\% v/v was used as mobile phase and was filtered before use, through $0.45 \mu$ membrane filter. A constant flow of $1.0 \mathrm{ml} / \mathrm{min}$ was maintained throughout the analysis. Detection was carried out using PDA detector at $210 \mathrm{~nm}$.

\section{c) Preparation of Stock Standard Solution}

Stock standard solution was prepared by dissolving $100 \mathrm{mg}$ of Vildagliptin in $100 \mathrm{~mL}$ methanol that gives concentration of $100 \mu \mathrm{g} / \mathrm{mL}$.

\section{d) Optimization of Detection Wavelength}

PDA detector was used, as it is reliable and easy to set at the correct wavelength. A fixed concentration of analyte was analyzed at different wavelengths.

\section{e) Calibration Curve by HPLC:}

From stock solution $(1000 \mu \mathrm{g} / \mathrm{mL})$, aliquots of $0.1,0.2,0.3,0.4,0.5,0.6 \mu \mathrm{L}$ were taken by pipette $(1 \mathrm{~mL})$ in series of $10 \mathrm{~mL}$ volumetric flask and diluted up to the mark with mobile phase to obtain concentration in the range of $10-60 \mu \mathrm{g} / \mathrm{mL}$ for Vildagliptin. A constant volume $20 \mu \mathrm{L}$ of Vildagliptin containing solution is injected into column with the help of microliter syringe. All measurements were repeated three times for each concentration and calibration curve is constructed by plotting the peak area (AUC) versus the drug concentration.

\section{F. Determination of IR spectrum ${ }^{[14]}$ :}

The IR spectra of drug sample were recorded by using $\mathrm{KBr}$ pellet method. The drug was triturated in porcelain mortar pestle with dry potassium bromide in ratio (1:100). The pellets were prepared in $\mathrm{KBr}$ press at pressure 10 tones. The pellet was scanned over the range of 4000- 
$400 \mathrm{~cm}^{-1}$ on Bruker FT-IR spectrophotometer. The identified peaks were compared with the principle peaks of reported IR spectrum of Vildagliptin and the sample was authenticated.

\section{G. DSC study ${ }^{[15]}$ :}

Differential Scanning Calorimetry thermogram of Timolol maleate was recorded by talking sample which was hermetically sealed in aluminium pans and heated at a constant rate of $20^{\circ} \mathrm{C} / \mathrm{min}$ over temperature range of 100 to $300^{\circ} \mathrm{C}$. Inert atmosphere was maintained by purging nitrogen gas at flow rate of $50 \mathrm{ml} / \mathrm{min}$.

\section{H. Compatibility studies:}

The drug excipients interaction study was carried out using Fourier Transform Infrared spectroscopy (FT-IR) after storage under accelerated conditions of temperature and relative humidity $\left(40^{\circ} \mathrm{C}, 75 \% \mathrm{RH}\right.$, for 28 days) as per ICH guidelines.

\section{FTIR spectroscopy study}

FT-IR spectra of Vildagliptin(pure drug), Vildagliptin with HPMC, Vildagliptin with Maltodextine, Vildagliptin with Polyethylene oxide. All drug and excipient was mixed with potassium bromide $(\mathrm{KBr})$ of IR grade in the ratio of 1:100 and compressed using motorized pellet press (Kimaya Engineers, India). The pellets were then scanned using FT-IR spectrophotometer (Shimadzu 8400S, Japan). The FT-IR spectra of mixtures were compared with that of the FT-IR spectra of pure drug and excipients.

\section{Formulation \& development}

\section{Screening of polymers for film forming capacity:}

Hydroxypropylmethyl cellulose (HPMC) is known for its good film forming properties and has excellent acceptability. Hence, various grades of HPMC namely M7ethocel K4M, Methocel K 15 and Methocel E50 Premium LV also various water soluble polymers PVA, Gelatin, and PVP K-30 were evaluated as a primary film former. For the fabrication of films, glycerin was used as a plasticizer, tween 80 as surfactant and aspartame was used as a sweetener.

\section{Calculation for number of strips:}

Diameter of petridish $=9 \mathrm{~cm}$

Surface area of petridish $=71.76 \mathrm{~cm}^{2}$

Number of strips obtained $=18$

*size $4 \mathrm{~cm}^{\mathrm{z}}$

\section{Preparation of drug loaded mouth dissolving film:}

The aqueous solution was prepared by dissolving polymers, plasticizers and the other components of the placebo formulations in distilled water and stirred with a magnetic stirrer. 
Then the active ingredient was added in the specific proportion to the obtained solution. The solution was stirred for $1 \mathrm{~h}$ and it was allowed to be kept aside for $2 \mathrm{~h}$ to remove air bubbles, and then $10 \mathrm{ml}$ of the solution was cast onto a glass petridish having a surface area of $71.76 \mathrm{~cm}^{2}$. The film solution was dried in a hot air oven at $45-50^{\circ} \mathrm{C}$. After drying, the films were removed with the help of a sharp blade and kept in a desiccator for $24 \mathrm{~h}$ before cutting it into small pieces, having an area of $4 \mathrm{~cm}^{2}$ for each film. Films with air bubbles, cuts, or imperfections were excluded from further study. Selected films were subjected to different evaluation parameters.

\section{Evaluation of mouth dissolving film ${ }^{[17]}$ :}

1. Weight variation

2. Disintegration time

3. Thickness of film

4. Tensile strength

5. Percent (\%) Elongation

6. Folding endurance

7. Percent moisture loss

8. Surface $\mathrm{pH}$

9. Dissolving time

10. Content uniformity

11. In-vitro drug release studies

12. Ex vivo drug diffusion study

13. Stability study of optimized formulation

\section{Weight variation of the film:}

$2 \times 2 \mathrm{~cm}^{2}$ film was cut at five different places in the caste film. The weight of each filmstrip was taken on digital analytical balance and the weight variation was calculated and the results are given in the Table.

\section{Disintegration time:}

Two methods were used for disintegration time of film, they are as follows:

\section{Drop method/Slide frame method:}

In the first method one drop of distilled water was dropped by a pipette onto the oral films. Therefore the films were placed on a glass slide and placed planar on a petridish. The time until the film dissolved and caused a hole within film was measured.

\section{Petridish method}

In this method $2 \mathrm{ml}$ of distilled water was placed in a petridish and one film was added on the 
surface of the water and the time required until the oral film was dissolved completely was measured. Drug-loaded films were investigated under both methods. Typical disintegration time for strips is $5-30$ seconds.

\section{Thickness of film:}

The thickness of film was evaluated using vernier caliper with range $0-10 \mathrm{~mm}$ and revolution $0.001 \mathrm{~mm}$ at different strategic locations. Anvil of the thickness gauge was turned and the film was inserted after making sure that pointer was set to zero. The film washed on the anvil and the reading on the dial was noted down. The average of 3 readings was taken. This is essential to ascertain uniformity in the thickness of the film as this is directly related to the accuracy ofdose in the strip.

\section{Tensile strength:}

Tensile strength is the maximum stress applied to a point at which the strip specimen breaks. It is calculated by the applied load at rupture divided by the cross-sectional area of the strip as given in theequation below:

Tensile strength $\quad=\quad$ Load of failure Strip thickness x strip width X 100

It was measured using Universal testing apparatus. The film of size $2 \times 2 \mathrm{~cm}^{2}$ and free of physical imperfections was placed between two clamps held $10 \mathrm{~mm}$ apart. The film was pulled by clampat a rate of $5 \mathrm{~mm} / \mathrm{min}$. Whole experiment was carried out in triplicate. The average of 3 readings was taken.

\section{Percent elongation:}

When stress is applied, a strip sample stretches and this is referred to as strain. Strain is basically the deformation of strip divided by original dimension of the sample. Generally elongation of strip increases as the plasticizer content increases. Percentage elongation was calculated by measuring the increase in length of the film after tensile strength measurement by using the following formula.

$$
\text { Percent elongation } \quad=\quad[\mathrm{L}-\mathrm{L} 0] / \mathrm{L} 0 \times 100
$$

Where, $\mathrm{L}=$ Final length, $\mathrm{L} 0=$ initial length

The average of 3 readings was taken and the data was given in table 7.11.

\section{Folding endurance}

Folding endurance is determined by repeated folding of the strip at the same place till the strip breaks. The number of times the film is folded without breaking is computed as the folding endurance value. 


\section{Percent moisture loss:}

The percent moisture loss studies were carried out to check the physical stability and integrity of the films. In the present study the moisture loss capacity of the films was determined by placing the known weight and predetermined size $(2 \mathrm{~cm} \times 2 \mathrm{~cm})$ of films in desiccator containing fused anhydrous calcium chloride (inside the desiccator) for $72 \mathrm{~h}$. After $72 \mathrm{~h}$ the films were removed and reweighed, and the average percentage moisture loss of the films was measured by using the formula,

Percent moisture loss $=\quad$ initial weight - final weight $/$ initial weight $\times 100$

\section{Surface pH:}

The film to be tested was placed in a petridish and was moistened with $0.5 \mathrm{ml}$ of distilled water and kept for $1 \mathrm{hr}$. The $\mathrm{pH}$ was noted after bringing the electrode of the $\mathrm{pH}$ meter in contact with the surface of the formulation and kept for $1 \mathrm{~min}$ to allow equilibrium condition.

\section{In vitro dissolving time:}

The dissolving time was determined by placing the film in a beaker containing $50 \mathrm{ml}$ of phosphate buffer ( $\mathrm{pH}$ 6.8). Time required by the film to dissolve completely was noted.

\section{Content uniformity:}

This is determined by any standard assay method described for the particular API in any of the standard pharmacopoeia. Content uniformity is determined by estimating the API content in individual strip. Limit of content uniformity is $98-102 \%$. A circular film of $2 \mathrm{~cm} 2 \mathrm{~cm}$ was cut and placed in a beaker containing $50 \mathrm{ml}$ of phosphate buffer $\mathrm{pH} 6.8$ solutions. The contents were stirred in magnetic stirrer to dissolve the film and the contents were transferred to a $50 \mathrm{ml}$ volumetric flask. The absorbance of the solution was measured against the corresponding blank solution at $276 \mathrm{~nm}$.

\section{In-vitro dissolution studies:}

Dissolution study was carried out in USP paddle type apparatus using $250 \mathrm{~mL}$ of phosphate buffer solution $(\mathrm{pH}$ 6.8) as a dissolution medium at $50 \mathrm{rpm}$.Temperature of the dissolution medium was maintained at $37 \pm 0.5^{\circ} \mathrm{C}$. Samples of $5 \mathrm{ml}$ were withdrawn at every 30 seconds interval, filtered (through $0.45 \mu$ ) andreplaced with $5 \mathrm{ml}$ of freshdissolution medium.Drug concentration estimated spectrophotometrically at $276 \mathrm{~nm}$ by using UV Win $3000^{+}$double beam UV-Visible spectrophotometer. The dissolutionexperiments were conducted in triplicate. Dissolution rate was studied for all designedformulations and dissolution parameters were calculated. 
Table 4: Conditions for evaluation of percent drug release

\begin{tabular}{lll}
\hline Sr. No. & Specification & Standard values \\
\hline 1 & Apparatus & USP dissolution apparatus I \\
2 & Speed & $50 \mathrm{rpm}$ \\
3 & Volume of media & $500 \mathrm{ml}$ \\
4 & Dissolution media & $\mathrm{pH} 6.8$ phosphate buffer solution \\
5 & Type & Basket type. \\
6 & Aliquot taken at each time interval & $5 \mathrm{ml}$. \\
& of 15 seconds & $37 \pm 0.5^{\circ} \mathrm{C}$. \\
7 & Temperature & $276 \mathrm{~nm}$ \\
\hline
\end{tabular}

\section{Kinetics modelling of drug dissolution profiles:}

The dissolution profile of all the batches was fitted to Zero order, First order to as certain the kinetic modelling of the drug release.

\section{A) Zero order}

In many of the modified release dosage forms, particularly sustained or controlled release dosage forms (those dosage forms that release the drug in planned, predictable and slower than the normal manner), is zero-order kinetic.

$\mathrm{m}=\mathrm{k} * \mathrm{t}$

Where, $\mathrm{k}$ is zero-order constant, $\mathrm{m}$ is the percent drug unreleased and $\mathrm{t}$ is the time. The plot of percent drug unreleased (released) versus time is the linear.

\section{B) First order}

Most conventional dosage forms exhibits this dissolution mechanism. Some modified releasee preparation, particularly prolonged release formulations, adheres to this type of dissolution pattern.

$$
\mathrm{m}=\mathrm{ea} * \mathrm{e}-\mathrm{bt}
$$

Where $a$ is the intercept and $b$ is the slop. It assumes that the drug molecules, diffuses out through a gel like layer formed around the drug during the dissolution process. A plot of $\log$ $\%$ drug release versus time is the linear.

\section{Ex-vivo drug diffusion studies:}

Ex vivo permeation studies through porcine oral mucosa of sheep (ventral surface of tongue) was carried out using the Franz diffusion cell of internal diameter of $2.5 \mathrm{~cm}$. The buccal mucosa was excised and trimmed evenly from the sides, washed in isotonic phosphate buffer of $\mathrm{pH} 6.8$ and used immediately. The membrane was stabilized before mounting to remove the soluble components. The mucosa was mounted between the donor and receptor compartments. The 
receptor compartment was filled with $15 \mathrm{ml}$ of isotonic phosphate buffer of $\mathrm{pH} 7.4$ which was maintained at $37 \pm 0.2^{\circ} \mathrm{C}$ and hydrodynamics were maintained using magnetic stirrer. One film of dimension $2 \mathrm{~cm} 2 \mathrm{~cm}$ was placed in donor compartment. The donor compartment was filled with $1 \mathrm{ml}$ of $\mathrm{pH}$ 6.8phosphate buffer. $1 \mathrm{ml}$ samples from receptor compartment were withdrawn at suitable time interval which was then replaced with $1 \mathrm{ml}$ of $\mathrm{pH} 7.4$ phosphate buffer. The percentage Vildagliptin permeated was determined by measuring the absorbance in UV-Visible spectrophotometer at $\lambda_{\max }$ of $276 \mathrm{~nm}$.

\section{Stability studies:}

Stability studies on the optimized formulation of oral fast dissolving film is carried out to determine the effect of temperature and humidity on testability of the drug. The film can be stored in an aluminium foil and subjected to stability at room temperature. The sample can withdraw at same days and subjected for disintegration test and in vitro dissolution studies to determine disintegration time and cumulative \% drug release. Selected film was stored at storage condition $40{ }^{\circ} \mathrm{C} / 75 \% \mathrm{RH}$. Each film was wrapped in a butter paper followed by aluminium foil and placed in an aluminium pouch, which was heat-sealed at the end. The films were evaluated for appearance, weight, Vildagliptin content, surface $\mathrm{pH}$, in vitro disintegration time and in vitro drug release after storage for 30, 60 and 90 days.

\section{Preformulation study:}

Preformulation studies were performed for the obtained sample of Vildagliptin and excipients for identification and compatibility studies was successfully carried out.

\section{Characterization of drug:}

The sample of Vildagliptin procured for study was identified and estimated for its purity. The sample was identified by melting point, $\mathrm{pH}$, UV spectrum, IR spectrum and differential scanning calorimetry etc.

\section{A. Organoleptic properties:}

Solid, white to slightly beige powder

B. $\mathrm{pH}$ :

$\mathrm{pH}$ of $2.0 \% \mathrm{w} / \mathrm{v}$ solution was found to be 5.4

\section{Determination of melting point:}

Melting point of Vildagliptin determined by open capillary tube method was $138 \pm 2$ to $140 \pm 1{ }^{\circ} \mathrm{C}(n=3)$. This value is same as that of the literature citation of $140^{\circ} \mathrm{C}$, thus indicating purity of the drug sample. Any impurity, if present, will cause variation in the melting point of a given drug substance. 


\section{Solubility determination}

Vildagliptin was found to be insoluble in water, but soluble in methanol and ethanol. It was sparingly soluble in chloroform.

\section{E. HPLC:}

\section{Optimization of Detection Wavelength}

PDA detector was used, as it is reliable and easy to set at the correct wavelength. A fixed concentration of analyte was analyzed at different wavelengths. As per the response of analyte, $210 \mathrm{~nm}$ wavelength was selected.

\section{Table 5: Final Chromatographic Conditions}

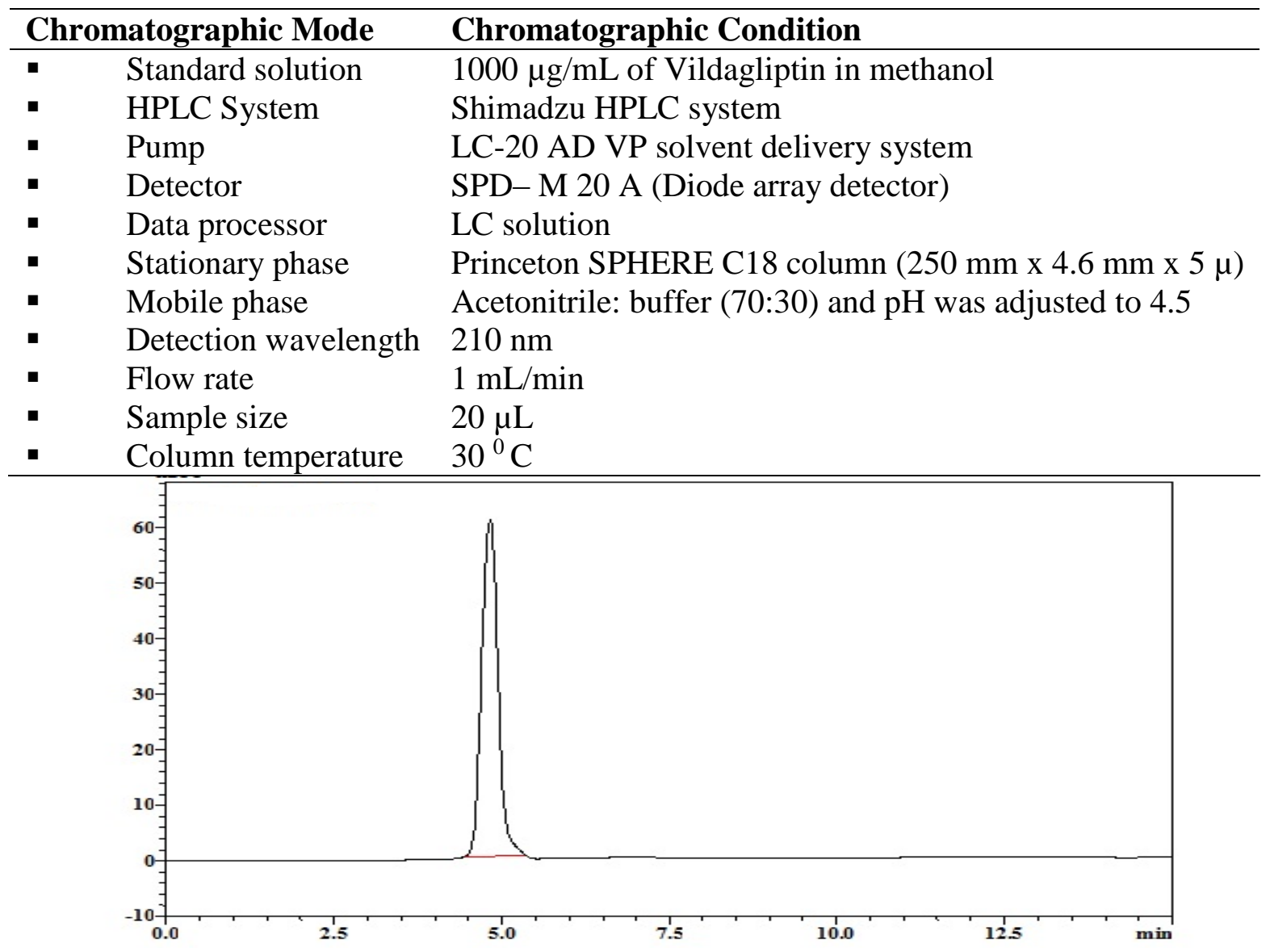

Figure 1: HPLC chromatogram of Vildagliptin

Table 6: Absorbance's of different conc. of Vildagliptin

\begin{tabular}{ll}
\hline Concentration $(\mathbf{u g} / \mathbf{m L})$ & Mean AUC \\
\hline 10 & 96990 \\
20 & 207460 \\
30 & 285632 \\
40 & 374563 \\
50 & 469944 \\
60 & 559898 \\
\hline
\end{tabular}




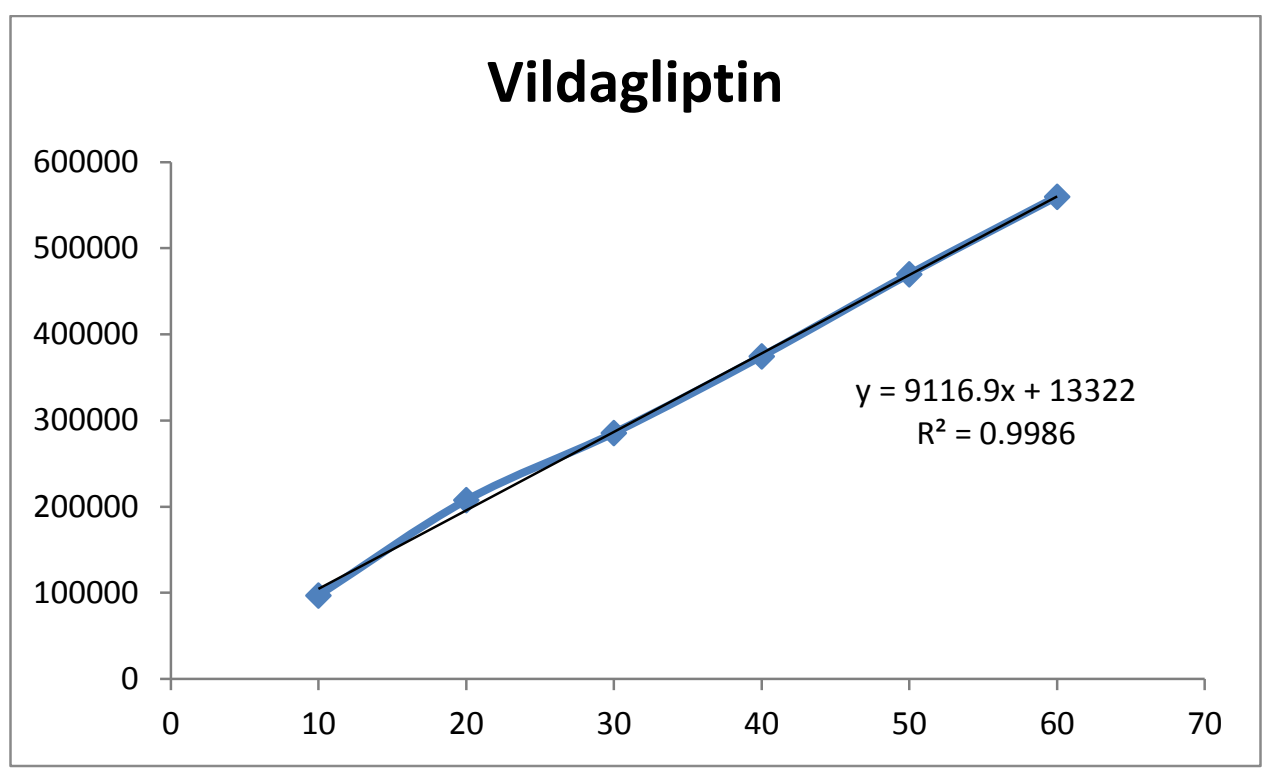

Figure 2: Calibration curve of Vildagliptinin PH 6.8

\section{F. IR Spectroscopy:}

The IR spectrum of the pure vildagliptin sample recorded by FTIR spectrometer is shown in Figure 5. Experimental spectra of vildagliptin is similar to reference spectra of vildagliptin reported in literature.

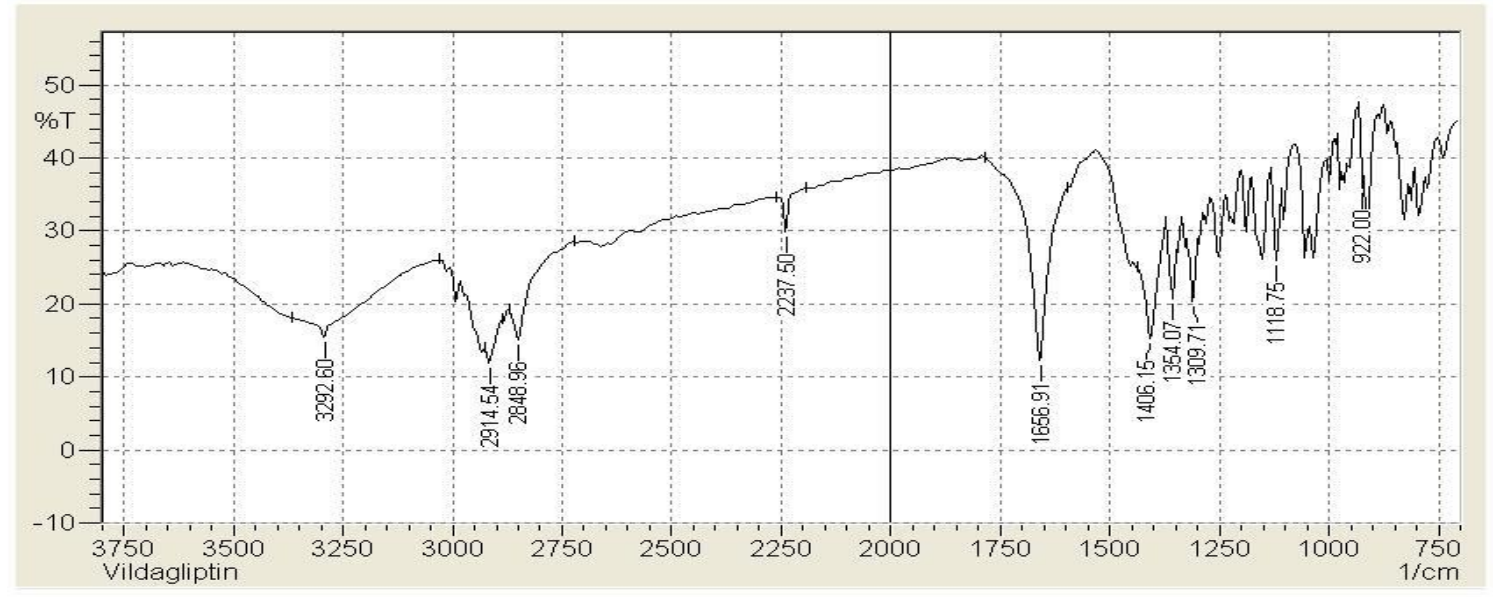

Figure 3: Standard IR Spectra of Vildagliptin

Table 7: Peaks observed in Spectrum of Vildagliptin

\begin{tabular}{lll}
\hline Sr. no. & Type of Peak & Observed wavenumber $\left(\mathbf{c m}^{-\mathbf{1}}\right)$ \\
\hline 1 & C-H stretching & 2914.54 \\
2 & C-H stretching & 2848.96 \\
3 & C $\Xi$ N Stretching & 2237.50 \\
4 & C=O stretching & 1656.91 \\
5 & O-H stretching & 3292 \\
6 & C-C stretching & 1406.15 \\
7 & C-N stretching & 1118.75 \\
\hline
\end{tabular}




\section{G. DSC studies:}

Melting point of Vildagliptin was measured by using DSC (Metler Toledo), Showed melting point of $140^{\circ} \mathrm{c}$ (Figure 7 ) which is similar as reported in literature.

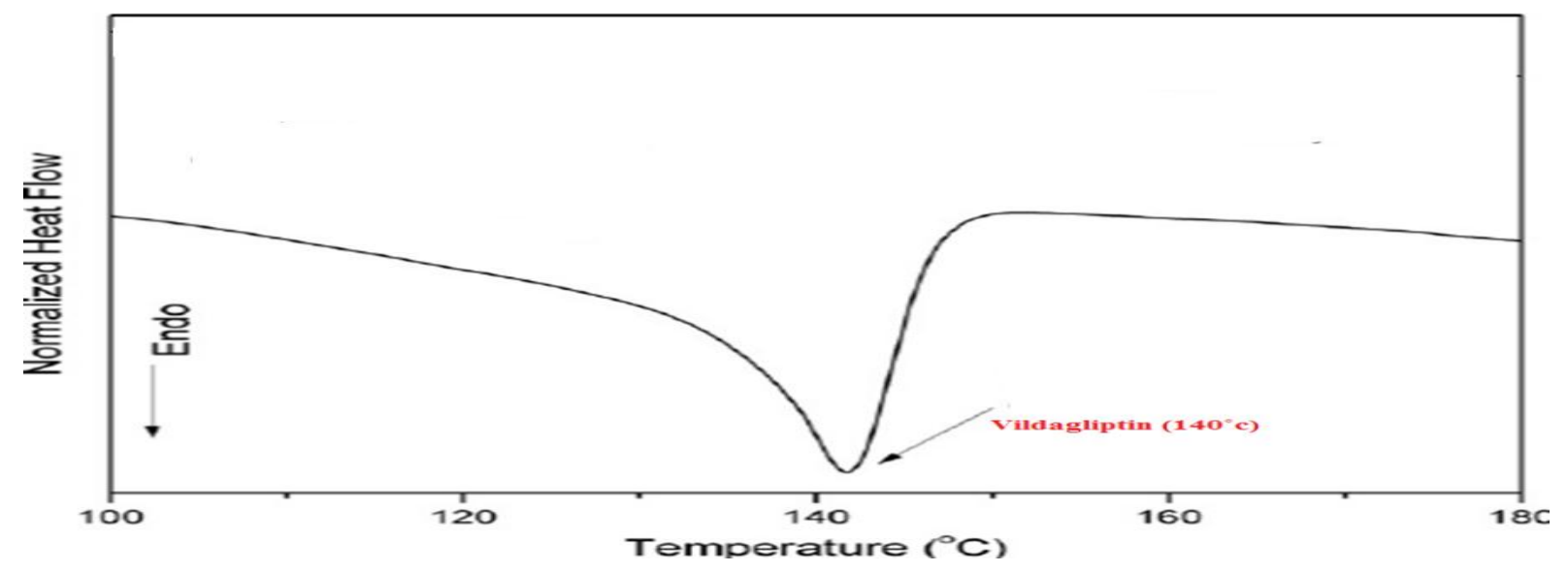

Figure 4: DSC of Vildagliptin

\section{Characterization of Excipients}

\section{A. Description:}

The descriptions of all the additives were similar to those reported in the literature as shown in table 17 .

Table 8:Description of formulation excipients

\begin{tabular}{ll}
\hline Name of excipients & Observation \\
\hline Maltodextrin & $\begin{array}{l}\text { Maltodextin occurs as a non sweet, odourless, white powder or } \\
\text { granules. }\end{array}$ \\
$\begin{array}{l}\text { Poly Ethylene Oxide } \\
\text { HydroxyPropyl Methyl } \\
\text { Cellulose }\end{array}$ & $\begin{array}{l}\text { White to off-white, free-flowing powder. Slight ammoniac odour. } \\
\text { Citric Acid }\end{array}$ \\
Occurs as colorless or translucent crystals, or as a white It is odourless \\
and has a strong acidic taste. The crystal structure is orthorhombic. \\
and occurs as an off white, almost odorless crystalline powder with an \\
Intensely sweet taste. \\
Glycerin is clear, colorless, odorless, viscous, and hygroscopic liquid; \\
Tween 80 & $\begin{array}{l}\text { it has a sweet taste, approximately 0.6 times as sweet as sucrose. } \\
\text { It have a characteristic odor and a warm, somewhat bitter taste, their } \\
\text { color \& physical form at } 25^{\circ} \mathrm{C} \text { are yellow oily liquid. }\end{array}$ \\
Ethanol & $\begin{array}{l}\text { It is a clear, colorless, mobile, and volatile liquid with as light, } \\
\text { characteristic odor and burning taste. }\end{array}$ \\
Water & Water is a clear, colorless, odourless, and tasteless liquid. \\
\hline
\end{tabular}

\section{B. Determination of solubility:}

All the excipients were found to be soluble in water and ethanol as described in literature. Thus solubility characteristics of all the excipients in various solvents were complying with literature. 
Table 9: Solubility of Excipients in Different Solvents

\begin{tabular}{|c|c|c|}
\hline Sr.no. & $\begin{array}{l}\text { Name of the } \\
\text { excipients }\end{array}$ & Name of the solvents \\
\hline 1. & Maltodextrin & Water; slightly soluble in ethanol (95\%). \\
\hline 2. & Poly Ethylene Oxide & water and acetonitrile, chloroform, \\
\hline 3. & $\begin{array}{l}\text { Hydroxy Propyl } \\
\text { Methyl Cellulose }\end{array}$ & $\begin{array}{l}\text { Cold water, mixtures of ethanol and dichloromethane, mixtures of } \\
\text { methanol and dichloromethane, and mixtures of water and alcohol. }\end{array}$ \\
\hline 4. & Citric Acid & $\begin{array}{l}\text { Soluble } 1 \text { in } 1.5 \text { parts of ethanol }(95 \%) \text { and } 1 \text { in less than } 1 \text { part of } \\
\text { water; sparingly soluble in ether }\end{array}$ \\
\hline 5. & Aspartame & Soluble in ethanol $(95 \%)$; sparingly soluble in water. \\
\hline 6. & Glycerine & Miscible with Water, slightly Soluble in acetone \\
\hline 7. & Tween 80 & Water ethanol \\
\hline 8. & Ethanol & Miscible with chloroform, ether, glycerine, and water \\
\hline 9. & Water & Miscible with most polar solvents. \\
\hline
\end{tabular}

\section{Determination of pH:}

All the formulations were checked for its $\mathrm{pH}$ values of aqueous solution using digital $\mathrm{pH}$ meter and $\mathrm{pH}$ values were quoted in table 7,6 .

Table 10: pH Values of Formulation Ingredients

\begin{tabular}{llll}
\hline Sr. no. & Name of excipients & Reported pH & Observed pH \\
\hline 1 & Maltodextrin & $4-7$ & $5.6-5.9$ \\
2 & Poly Ethylene Oxide & $4.5-7$ & $4.5-7.1$ \\
3 & Hydroxy Propyl Methyl Cellulose & $5.0-7.5$ & $6.0-6.4$ \\
4 & Citric Acid & 2.2 & $2.3-2.4$ \\
5 & Aspartame & 4.3 & $4.1-4.6$ \\
6 & Glycerine & $6.9-7.6$ & $7-7.8$ \\
7 & Tween 80 & $5.5-7.5$ & $5.5-5.9$ \\
8 & Ethanol & 7 & $6.8-7.2$ \\
9 & Water & 7 & 7.2 \\
\hline
\end{tabular}

Thus, it was found that there was good agreement between the experimental and literature values of $\mathrm{pH}$ of various excipients.

\section{Determination of melting point}

Melting point of excipients determined by open capillary tube method. This value is same as that of the literature citation, thus indicating purity of the excipients. Any impurity, if present, will cause variation in the melting point of a given excipients.

Table 11: Melting point of Formulation Ingredients

\begin{tabular}{llll}
\hline Sr. no. & Name of excipients & Reported M.P. & Observed M.P. \\
\hline 1 & Maltodextrin & $240^{\circ} \mathrm{C}$ & $225^{\circ} \mathrm{C}$ \\
2 & Poly Ethylene Oxide & $67^{\circ} \mathrm{C}$ & $66-70^{\circ} \mathrm{Cc}$ \\
3 & Hydroxy Propyl Methyl Cellulose & $260^{\circ} \mathrm{C}$ & $256^{0} \mathrm{C}$ \\
4 & Citric Acid & $153^{\circ} \mathrm{C}$ & $157^{0} \mathrm{C}$ \\
5 & Aspartame & $146^{\circ} \mathrm{C}$ & $150^{\circ} \mathrm{C}$ \\
\hline
\end{tabular}




\begin{tabular}{llll}
\hline 6 & Glycerine & $17.8^{0} \mathrm{C}$ & $18^{0} \mathrm{C}$ \\
7 & Tween 80 & $20.55^{\circ} \mathrm{C}$ & $22^{0} \mathrm{C}$ \\
8 & Ethanol & $17.19^{0} \mathrm{C}$ & $15^{0} \mathrm{C}$ \\
\hline
\end{tabular}

\section{E. Compatibility studies:}

FT-IR spectra of Vildagliptin with HPMC (Figure no. 7.5), Vildagliptin with Maltodextrin(Figure no. 7.6) Vildagliptin with Polyethylene oxide(Figure no. 7.7)and overlay spectra are shown in Figure no. 7.8.

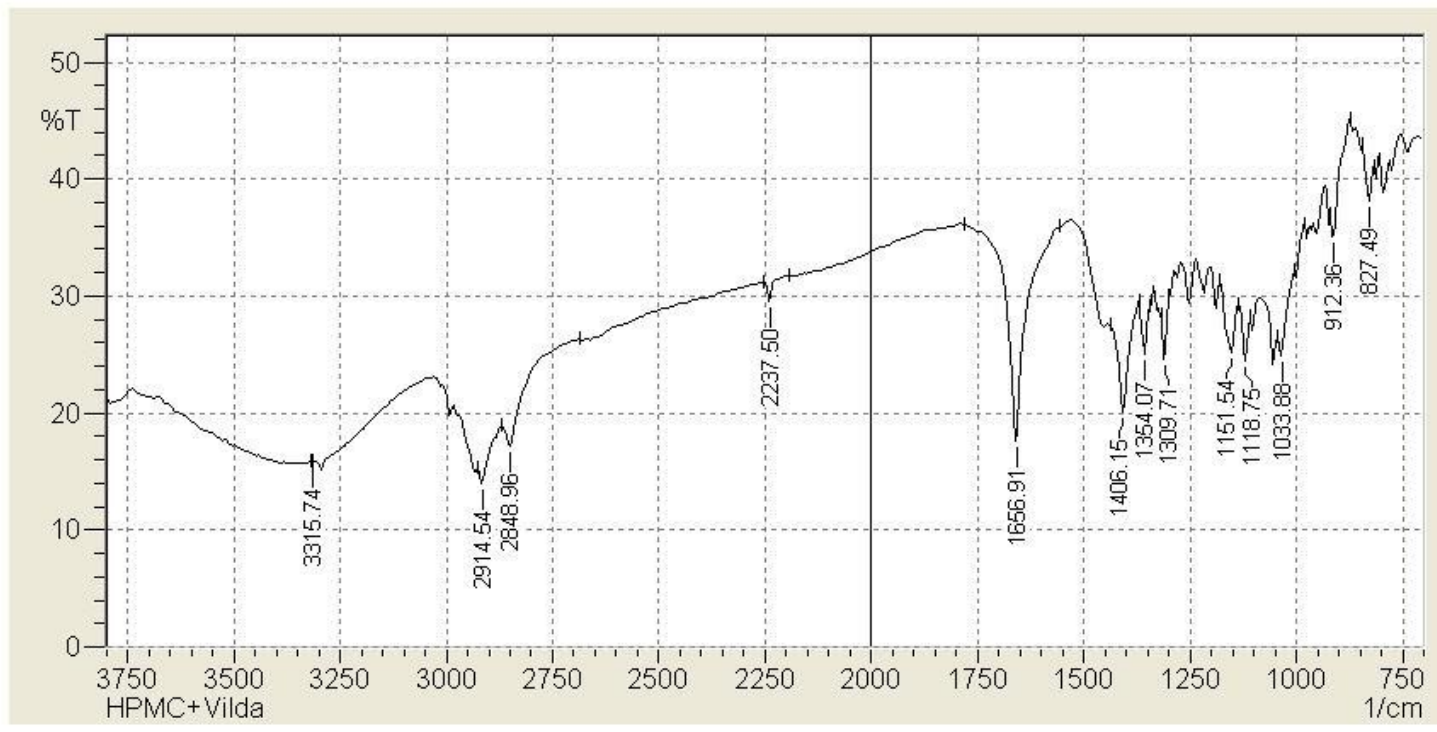

Figure 5: FTIR spectra of Vildagliptin with HPMC

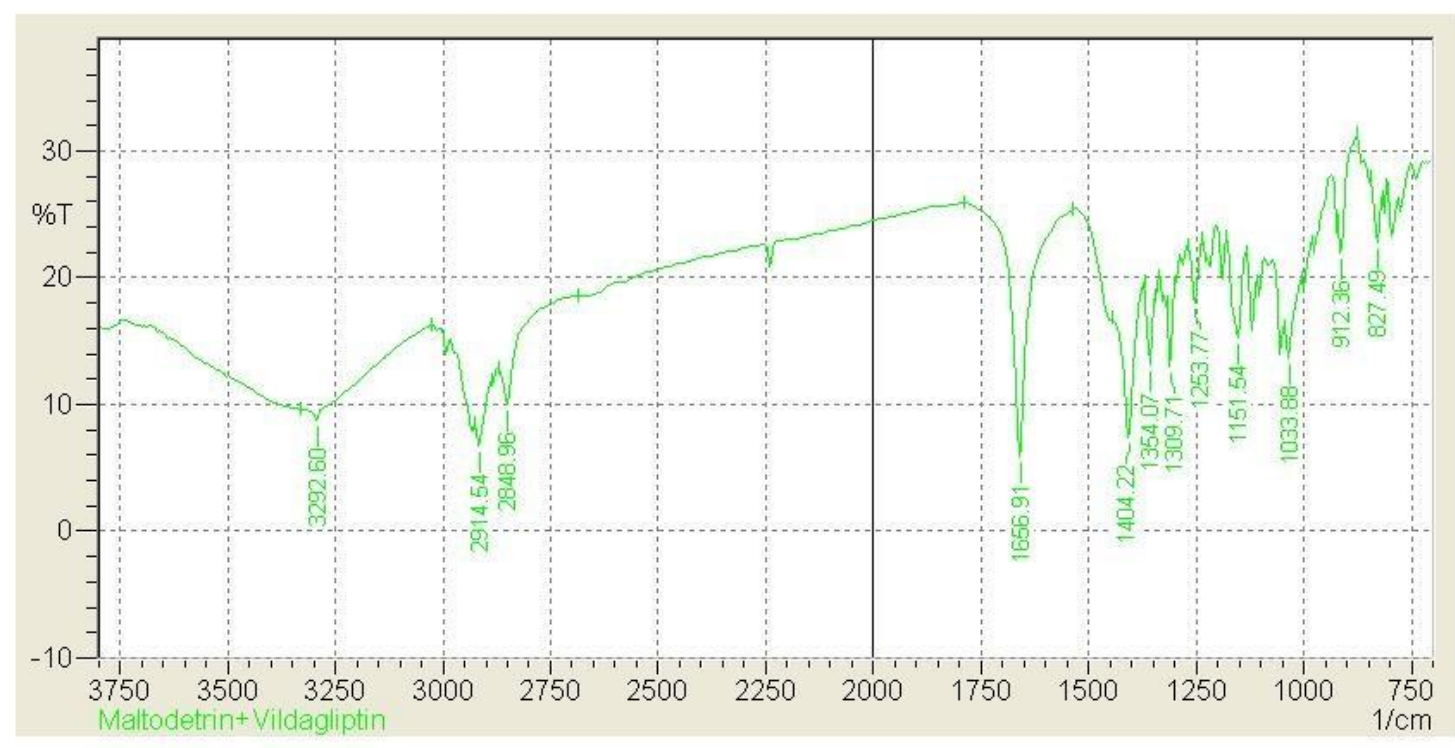

Figure 6: FTIR spectra of Vildagliptin with Maltodextrin 


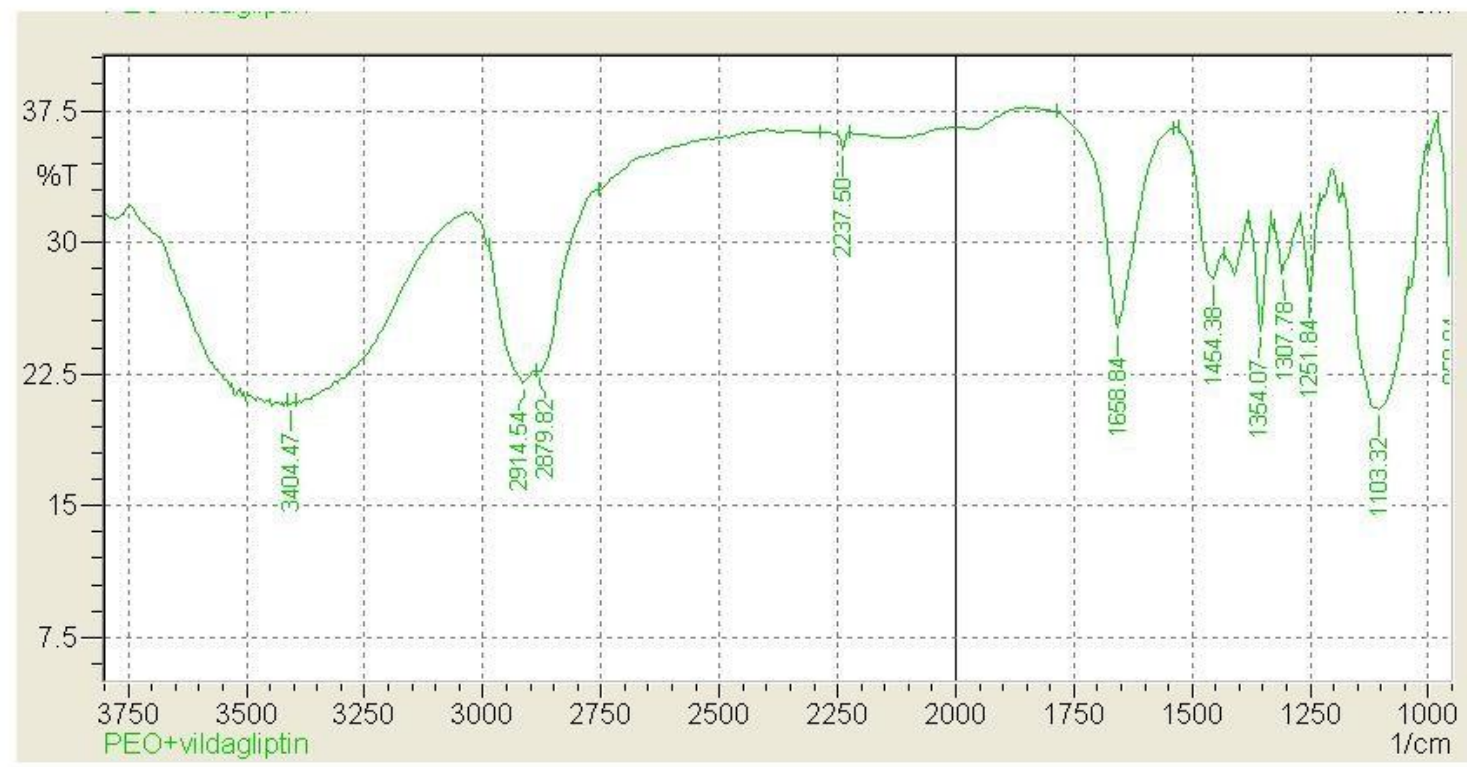

Figure 7: FTIR spectra of Vildagliptin with Polyethylene oxide

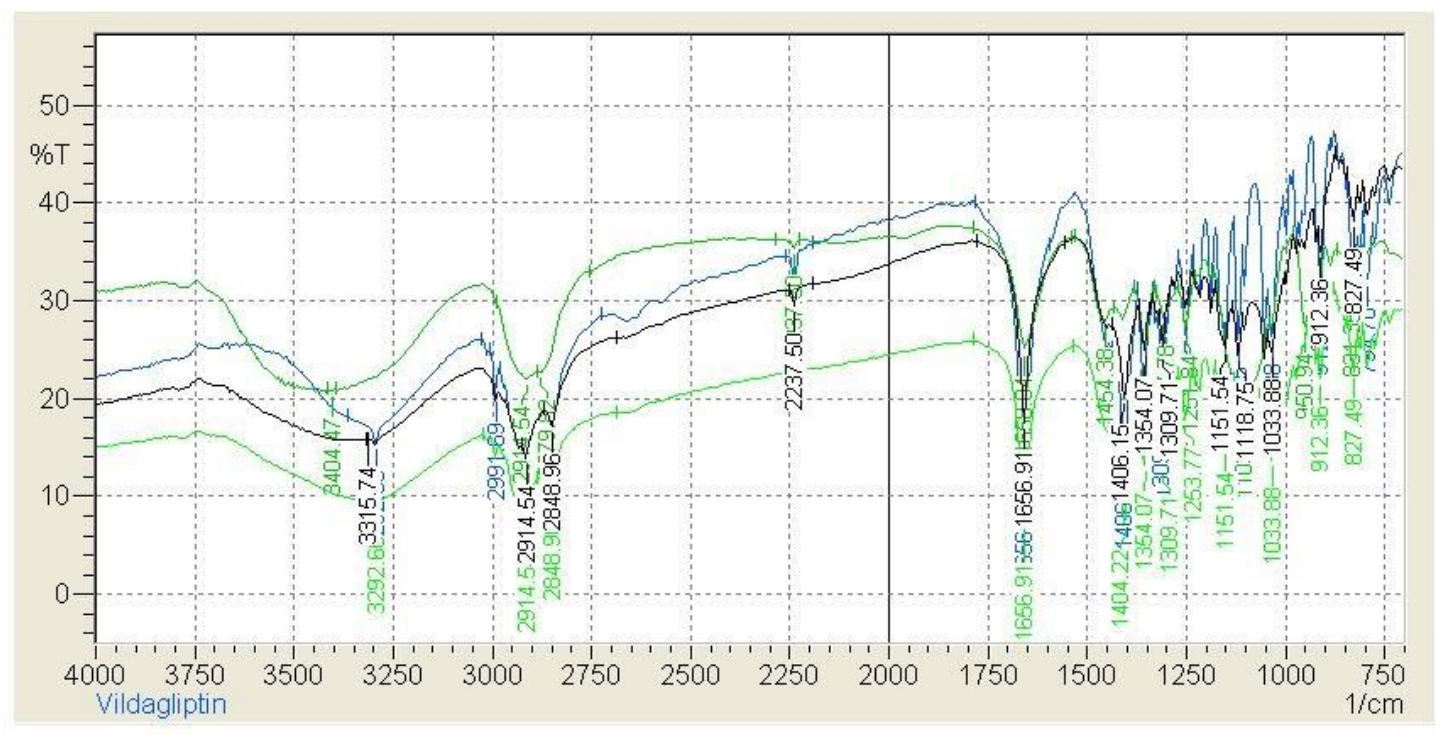

Figure 8: FTIR overlay spectra

The FTIR Spectra of pure drug and Drug: Excipient spectra is indicate that there is no sign of interaction drug and excipient was compatible with each other.

\section{Formulation and development:}

\section{Screening of polymers for film forming capacity:}

Determination of film forming capacity, visual appearance, disintegration time values for the films of formulations. PVP K-30, gelatin, and sodium alginate these polymers showed very poor strip forming capacity. Visual appearance of the films was transparent and free of bubbles, which is necessary for the aesthetic appeal of the films. The above evaluated parameter indicated that 
the HPMC K4M, K 15, E 50, PVA films have desired characteristic like film forming capacity and good visual appearance. The appearance of the strips were found to be semitransparent, transparent or no any appearance and disintegration time were varies according to nature of polymers. HPMC K4M and HPMC K 15 shows maximum disintegration time $81 \mathrm{sec}$ and $73 \mathrm{sec}$ hence excluded for the following study. The HPMC E 15, PVA and HPMC + PVA based strip formulation was showed best film formulation, lowest disintegration time $21 \mathrm{sec}, 32 \mathrm{sec}$ and 26 sec respectively and transparent in appearance. So that HPMC E 15, PVA was select as film forming polymer among the all polymers for the following study.

Formulation of drug loaded mouth dissolving film:
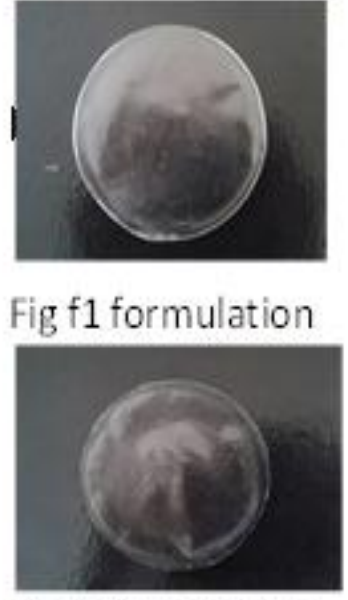

Fig f4 formulation

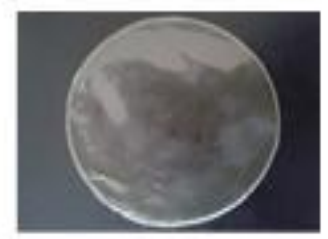

Fig $f 7$ formulation
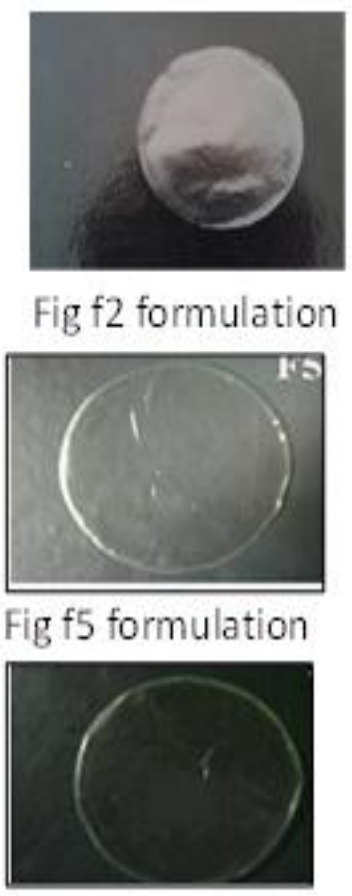

Fig f8 formulation

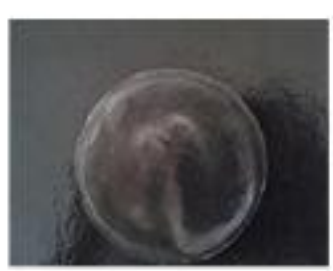

Fig f3 formulation
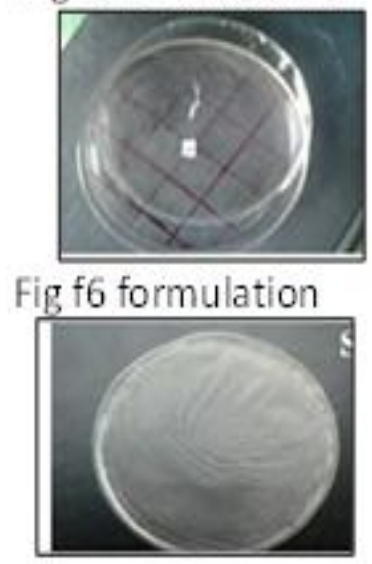

Fig f9 formulation

Figure 9: Different formulations of Vildagliptin of fast dissolving buccal films.

The formulations of fast dissolving buccal films were successfully formed with the help of solvent casting methods and all the formulations show even and bubble free film surface. The even and bubble free films were selected for the various evaluation parameters

\section{Evaluation parameters for films:}

\section{A. Weight variation of the films:}

Mouth dissolving films were prepared by casting method. Films each of $4 \mathrm{~cm}^{2}$ were cut at five different places from casted films and weight variation was measured. Weight variation varies

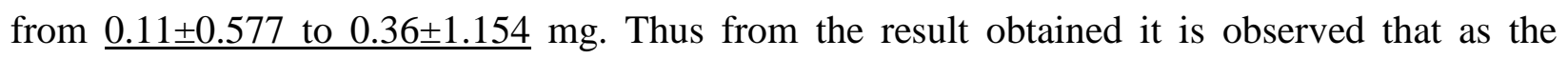


concentration and molecular weight of polymers are increasing, correspondingly the weight of film increasing. The results of weight variations are shown in the Table 7.8.

Table 12: Comparative evaluation of Weight variation of mouth dissolving films

\begin{tabular}{lll}
\hline Sr. no. & Formulation code & Mean \pm S.D. \\
\hline 1 & F1 & $0.12 \pm 0.577$ \\
2 & F2 & $0.11 \pm 0.577$ \\
3 & F3 & $0.13 \pm 1.154$ \\
4 & F4 & $0.34 \pm 0.577$ \\
5 & F5 & $0.36 \pm 1.154$ \\
6 & F6 & $0.29 \pm 0.577$ \\
7 & F7 & $0.22 \pm 0.214$ \\
8 & F8 & $0.17 \pm 0.574$ \\
9 & F9 & $0.15 \pm 1.154$ \\
\hline
\end{tabular}

\section{B. In vitro disintegration time:}

Disintegration times of the films were found to be increased with increase in the concentration of the polymer. The formulation F1 and F9 shows minimum $15 \mathrm{Sec}$ disintegration time as shown in the table. 22. HPMC E 15 based fast dissolving film were also prepared using two polymer like PEO Maltodextrin in order to study their role on disintegration time at different concentration. Disintegrates altered the disintegration behavior of fast dissolving film. HPMC E 15 films without disintegrates, on hydration, formed a soft pulpy mass before going into solution, while fast dissolving film containing disintegrates displayed bursting and fragmentation tendency. The increase in disintegration for these films may be due to higher water requirement by a larger amount of disintegrate which consequently transforms into swelling force for rapid disintegration. The HPMC based fast dissolving disintegration time is increased probably with PEO Maltodextrin due to formation of a non continuous film with high content of insoluble solids, which upon swelling retards the dissolution of HPMC.

Table 13: Comparative evaluation of In vitro disintegration time of mouth dissolving films

\begin{tabular}{lll}
\hline Sr. no. & Formulation code & $\begin{array}{l}\text { Disintegration time (sec) } \\
\text { Petri-plate method }\end{array}$ \\
\hline 1 & F1 & 16 \\
2 & F2 & 24 \\
3 & F3 & 16 \\
4 & F4 & 17 \\
5 & F5 & 15 \\
6 & F6 & 18 \\
7 & F7 & 19 \\
8 & F8 & 20 \\
9 & F9 & 22 \\
\hline
\end{tabular}




\section{Thickness of the film:}

The thickness of the drug loaded films was measured with the help of digital vernier caliper. The F5 had maximum thickness which is having three polymers. The average thickness of films increases with the increase in concentration and the molecular weight of the polymer. Thickness

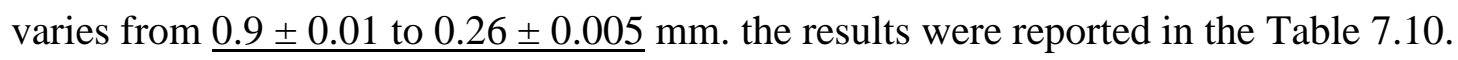

Table 14: Comparative evaluation of thickness of mouth dissolving films

\begin{tabular}{lll}
\hline Sr. no. & Formulation code & Mean \pm S.D. \\
\hline 1 & F1 & $0.12 \pm 0.01$ \\
2 & F2 & $0.9 \pm 0.01$ \\
3 & F3 & $0.13 \pm 0.005$ \\
4 & F4 & $0.19 \pm 0.005$ \\
5 & F5 & $0.26 \pm 0.005$ \\
6 & F6 & $0.20 \pm 0.01$ \\
7 & F7 & $0.17 \pm 0.005$ \\
8 & F8 & $0.14 \pm 0.01$ \\
9 & F9 & $0.15 \pm 0.01$ \\
\hline
\end{tabular}

Table 15: Tensile strength and Percentage elongation of mouth dissolving films

\begin{tabular}{llll}
\hline Sr. no. & Formulation code & $\begin{array}{l}\text { Tensile strength in kgs } \\
\text { (Mean } \pm \text { S.D.) }\end{array}$ & $\begin{array}{l}\text { Percent elongation } \\
\text { (Mean } \pm \text { S.D.) }\end{array}$ \\
\hline 1 & F1 & $1.126 \pm 0.6584$ & $19.18 \pm 0.1428$ \\
2 & F2 & $1.359 \pm 0.6254$ & $23.13 \pm 0.0157$ \\
3 & F3 & $1.396 \pm 0.3624$ & $24.13 \pm 0.1547$ \\
4 & F4 & $1.429 \pm 0.3654$ & $15.19 \pm 1.1487$ \\
5 & F5 & $1.562 \pm 0.7541$ & $26.13 \pm 1.0254$ \\
6 & F6 & $1.554 \pm 0.1295$ & $18.45 \pm 0.1764$ \\
7 & F7 & $1.486 \pm 0.9543$ & $22.47 \pm 0.1154$ \\
8 & F8 & $1.426 \pm 0.3264$ & $26.47 \pm 1.0248$ \\
9 & F9 & $1.352 \pm 0.2654$ & $37.10 \pm 0.1684$ \\
\hline
\end{tabular}

From the results it is clear that when the concentration of the polymer increases, the tensile strength of the film also increases. The film made up of PEO and Maltodextrinhas higher tensile strength and percent elongation as compared to HPMC films. But the film F5 containing both HPMC and PEO, Maltodextrin shows less tensile strength and percent elongation as compare to PEO Maltodextrin film it is due to presence of HPMC in combination PEO, Maltodextrin decreases the mechanical property of PVA polymer. The formulation F9 containing less amount of HPMC as compare to other PEO, Maltodextrin shows the maximum value of tensile strength $1.562 \pm 0.7541 \mathrm{~kg}$ and percentage elongation $26.13 \pm 1.0254$ which contains higher concentration of PEO, Maltodextrin. 


\section{Folding endurance of the films:}

The folding endurance was measured manually. A strip of film $4 \mathrm{~cm}^{2}$ was cut and subjected for the folding endurance studies until it brake at the same place. The number of times the film fold until it broken.

Table 16: Folding endurance of the films.

\begin{tabular}{lll}
\hline Sr. no. & Formulation code & Mean \pm S.D. \\
\cline { 2 - 4 } 1 & F1 & $110 \pm 2.6$ \\
2 & F2 & $93 \pm 5.3$ \\
3 & F3 & $185 \pm 8.6$ \\
4 & F4 & $192 \pm 3.4$ \\
5 & F5 & $219 \pm 5.36$ \\
6 & F6 & $195 \pm 2.66$ \\
7 & F7 & $145 \pm 6.2$ \\
8 & F8 & $120 \pm 5.4$ \\
9 & F9 & $110 \pm 4.2$ \\
\hline
\end{tabular}

+ standard deviation $n=3$

From the results it is observed that folding endurance increases with increase in polymer concentration. Formulation F5, F6, F7 and F8 which contains PEO shows optimum folding endurance value of $219 \pm 5.36$

\section{E. Percent moisture loss studies:}

The percent moisture loss studies were carried out to check the physical stability and integrity of the films. The results obtained after performing percent moisture loss study on the various formulations were shown in table 7.13.From the results obtained after performing percent moisture loss study it was observed that the percent moisture loss varies from $17.3 \pm 0.00057$ to $4.9 \pm 0.057$.

Table 17: Percent moisture loss of mouth dissolving films

\begin{tabular}{lll}
\hline Sr. no. & Formulation code & Mean \pm S.D. \\
\hline 1 & F1 & $9.0 \pm 0.1$ \\
2 & F2 & $15.16 \pm 0.005$ \\
3 & F3 & $14.0 \pm 0$ \\
4 & F4 & $16.3 \pm 0.9$ \\
5 & F5 & $4.9 \pm 0.057$ \\
6 & F6 & $11.5 \pm 0.28$ \\
7 & F7 & $11.19 \pm 0.9$ \\
8 & F8 & $14.15 \pm 0.01$ \\
9 & F9 & $17.3 \pm 0.00057$ \\
\hline
\end{tabular}


Thus the formulation containing maximum concentration of PEO shows more percent moisture loss as compare to formulation containing HPMC it is may be due to higher permeability of PEO, Maltodextine polymer to the moisture.

\section{F. Surface pH:}

The surface $\mathrm{pH}$ of all the formulations were taken with the help of $\mathrm{pH}$ meter and results were note down in following table 7.14.

Table 18: Surface pH of mouth dissolving films

\begin{tabular}{lll}
\hline Sr. no. & Formulation code & Surface $\mathbf{p H} \pm$ S.D. $(\mathbf{n}=\mathbf{3})$ \\
\hline 1 & F1 & $5.65 \pm 0.11$ \\
2 & F2 & $5.81 \pm 0.1$ \\
3 & F3 & $6.5 \pm 0.15$ \\
4 & F4 & $5.16 \pm 0.05$ \\
5 & F5 & $6.18 \pm 0.1$ \\
6 & F6 & $5.83 \pm 0.55$ \\
7 & F7 & $5.81 \pm 0.11$ \\
8 & F8 & $6.10 \pm 0.11$ \\
9 & F9 & $5.58 \pm 0.5$ \\
\hline
\end{tabular}

From the result it was clear that all the formulation shows surface $\mathrm{pH}$ within acceptance range which was near the salivary $\mathrm{pH}$ (5.5 to 7$)$. Thus the results reveal that all the formulations provide an acceptable $\mathrm{pH}$ in the range of 5-6. Hence they may not produce any local irritation to the oral mucosal.

\section{G. Dissolving time:}

The dissolving time was determined and Time required by the film to dissolve completely was noted in table no 7.15 .

Table 19: In-vitro dissolving time of mouth dissolving films

\begin{tabular}{lll}
\hline Sr. no. & Formulation code & $\begin{array}{c}\text { Dissolving time(sec) } \pm \text { S.D. } \\
(\mathbf{n}=\mathbf{3})\end{array}$ \\
\hline 1 & F1 & $24.16 \pm 1.23$ \\
2 & F2 & $26.32 \pm 0.24$ \\
3 & F3 & $34.45 \pm 2.43$ \\
4 & F4 & $38.27 \pm 0.13$ \\
5 & F5 & $23.42 \pm 1.31$ \\
6 & F6 & $32.42 \pm 2.34$ \\
7 & F7 & $40.42 \pm 0.42$ \\
8 & F8 & $46.24 \pm 1.65$ \\
9 & F9 & $51.12 \pm 1.56$ \\
\hline
\end{tabular}

A rapid dissolution of all the film preparations was observed by the dissolution test . 


\section{H. Content uniformity:}

The prepared film formulations were analyzed for drug content and it was observed that all the drug content uniformity values between $91.66 \pm 0.652$ to99.69 \pm 0.364 which is acceptable within limit as per IP. The observed results of the content uniformity indicated that the drug was uniformly distributed throughout the film.

Table 20: Drug content of mouth dissolving films

\begin{tabular}{lll}
\hline Sr. no. & Formulation code & $\begin{array}{l}\text { Drug content }(\%) \pm \text { S.D. } \\
(\mathbf{n = 3})\end{array}$ \\
\hline 1 & F1 & $96.56 \pm 0.235$ \\
2 & F2 & $91.66 \pm 0.652$ \\
3 & F3 & $97.78 \pm 0.359$ \\
4 & F4 & $94.11 \pm 0.495$ \\
5 & F5 & $99.69 \pm 0.364$ \\
6 & F6 & $99.34 \pm 0.846$ \\
7 & F7 & $95.34 \pm 0662$ \\
8 & F8 & $92.89 \pm 0.581$ \\
9 & F9 & $91.44 \pm 0.653$ \\
\hline
\end{tabular}

\section{In vitro dissolution studies:}

It is observed from in vitro dissolution studies for the films instant drug release due to film instantly get wet by dissolution medium and disintegrate. Percentage of drug release at different time intervals are shown in the table 7.17.

Table 21: In-vitro dissolution data of MDF formulations F-1toF-9 phosphate buffer pH 6.8 solution

\begin{tabular}{llllll}
\hline \multirow{2}{*}{ Time } & \multicolumn{6}{l}{ Cumulative Percent Drug Released (average \pm S.D.) $(\mathbf{n}=3)$} \\
\cline { 2 - 6 } & F-I & F-2 & F-3 & F-4 & F-5 \\
\hline 15 & $22.41 \pm 1.40$ & $10.98 \pm 1.2$ & $30.57 \pm 0.2$ & $17.51 \pm 2.47$ & $66.49 \pm 1.34$ \\
30 & $32.6 \pm 1.23$ & $19.36 \pm 1.36$ & $55.67 \pm 1.65$ & $26.03 \pm 0.42$ & $84.15 \pm 0.32$ \\
45 & $46.36 \pm 0.21$ & $26.28 \pm 2.41$ & $69.84 \pm 1.42$ & $37.97 \pm 1.54$ & $92.33 \pm 1.45$ \\
60 & $55.43 \pm 1.07$ & $34.95 \pm 1.98$ & $82.63 \pm 1.73$ & $45.24 \pm 1.04$ & $97.38 \pm 1.45$ \\
120 & $66.29 \pm 1.34$ & $43.79 \pm 1.52$ & $90.75 \pm 1.75$ & $57.54 \pm 2.0$ & $99.23 \pm 2.51$ \\
240 & $74.09 \pm 1.53$ & $57.69 \pm 0.42$ & $94.1 \pm 1.65$ & $70.07 \pm 2.01$ & \\
360 & $90.17 \pm 1.65$ & $83.29 \pm 1.84$ & $99.12 \pm 1.84$ & $87.73 \pm 1.62$ & \\
480 & $98.39 \pm 2.64$ & $93.09 \pm 1.77$ & & $94.28 \pm 1.06$ & \\
600 & & $98.06 \pm 1.63$ & & $99.3 \pm 1.55$ & \\
720 & & & & & \\
\hline
\end{tabular}

\begin{tabular}{lllll}
\hline \multirow{2}{*}{ Time } & \multicolumn{4}{l}{ Cumulative } \\
\cline { 2 - 5 } & F-6 & F-7 & F-8 & F-9 \\
\hline 15 & $42 \pm 1.65$ & $24.04 \pm 1.65$ & $12.61 \pm 0.46$ & $9.35 \pm 2.00$ \\
30 & $67.33 \pm 0.27$ & $34.32 \pm 1.54$ & $21.03 \pm 1.51$ & $11.17 \pm 1.92$ \\
45 & $80.9 \pm 1.32$ & $48.06 \pm 1.62$ & $26.34 \pm 1.23$ & $21.18 \pm 1.16$ \\
\hline
\end{tabular}




\begin{tabular}{lllll}
\hline 60 & $89.81 \pm 1.93$ & $55.52 \pm 1.73$ & $35.02 \pm 1.05$ & $23.23 \pm 1.03$ \\
120 & $94.8 \pm 1.62$ & $68.02 \pm 1.72$ & $45.49 \pm 1.53$ & $26.95 \pm 1.92$ \\
240 & $98.22 \pm 1.83$ & $75.85 \pm 1.51$ & $57.79 \pm 1.62$ & $38.89 \pm 1.69$ \\
360 & & $93.6 \pm 0.31$ & $85.02 \pm 0.52$ & $65.75 \pm 1.74$ \\
480 & & $98.62 \pm 2.05$ & $93.17 \pm 1.94$ & $93.14 \pm 1.52$ \\
600 & & & $98.19 \pm 1.52$ & $96.56 \pm 2.64$ \\
720 & & & & $98.38 \pm 1.43$ \\
\hline
\end{tabular}

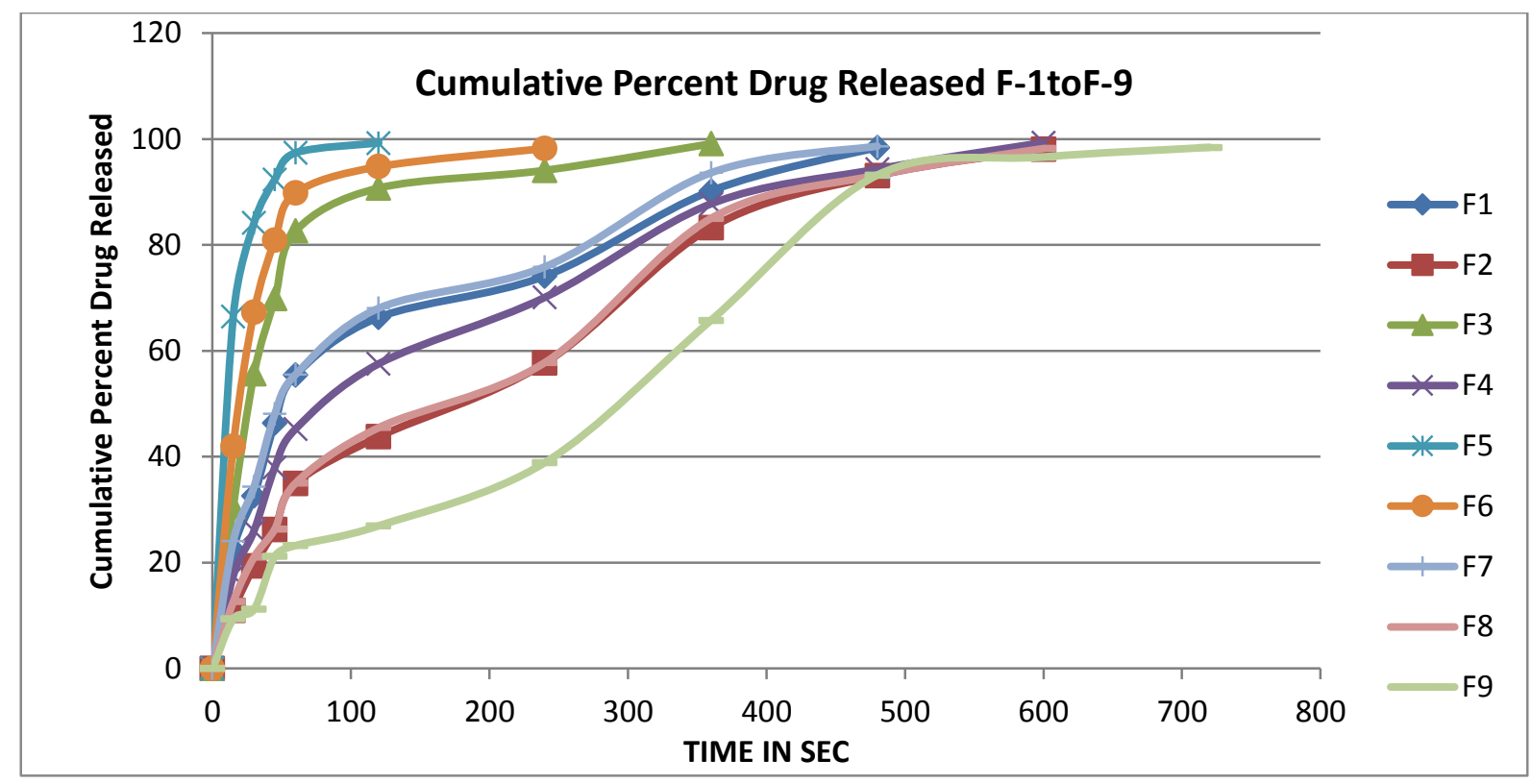

Figure 10: Cumulative percent drug released of formulationsF-1 - F-9

Kinetics modelling of drug dissolution profiles:

Table 22: In-vitro drug release kinetics of formulation

\begin{tabular}{llll}
\hline Sr. no. & Formulation code & $\begin{array}{l}\text { Zero order } \\
\mathbf{r}^{\mathbf{2}}\end{array}$ & $\begin{array}{l}\text { First order } \\
\mathbf{r}^{\mathbf{2}}\end{array}$ \\
\hline 1 & F1 & 0.271 & 0.992 \\
2 & F2 & 0.707 & 0.992 \\
3 & F3 & 0.363 & 0.986 \\
4 & F4 & 0.391 & 0.991 \\
5 & F5 & 0.671 & 0.995 \\
6 & F6 & 0.834 & 0.991 \\
7 & F7 & 0.671 & 0.995 \\
8 & F8 & 0.685 & 0.989 \\
9 & F9 & 0.846 & 0.992 \\
\hline
\end{tabular}

The in vitro drug release profiles of the formulations in $\mathrm{pH} 6.8$ phosphate buffer show differences depending on their composition as given in table 32. A rapid dissolution of all the film preparations was observed by the dissolution test, in which approximately $99.23 \%$ of Vildagliptin dissolved within 2 min. The formulations F4 and F3 showed approximately 100\% drug release within 8 minutes. It was also observed that HPMC E-15 was give superior result 
compare to Poly-ethylene oxide and Maltodextrin films. Also higher amount of film forming polymer resulted in release of drug at faster rate. Thus as the polymer concentration increases the rate of drug release increase. From the In-vitro dissolution data it is clear that F5 having highest concentration of polymer a gives best result. Results in above table which shows that the formulations containing minimum concentration of polymers is having higher release rate as compare to formulation containing minimum concentration of polymers. So drug release is purely influenced by polymer concentration. Formulations F1 contain HPMC E 15 shows better result than the formulation F2 and F4 containing Maltodextrin shows better result than the formulation F3 .Formulations F5 contain HPMC E 15, Maltodextrin, polyethylene oxide shows better result than the formulation F6, F7 and F8 in higher concentration containing shows better result formulation So HPMC E 15 and Maltodextrin is best polymer for the preparation of mouth dissolving film. Formulation F9 contains HPMC E 15 and in Maltodextrin, polyethylene oxide less concentration hence it shows formulation gives slow drug release due to presence of minimum concentration. The drug release obtained shows that combination of HPMC E 15, Maltodextrin, polyethylene oxide and gives better result than alone HPMC E 15 and Maltodextrin is due to presence of HPMC E 15 improves the properties of film. F5 formulation gives best result amongst the formulation due to presence of HPMC E 15 Maltodextrin, polyethylene oxide increases the dissolution rate. Drug release was in following order F5>F6 $>$ F7 $>$ F3 $>$ F4 $>$ F1 $>$ F8 $>$ F2 $>$.F9

\section{J.Ex vivo permeation study}

Table 23: Ex-vivo permeation of different formulations of fast dissolving films:

\begin{tabular}{llllll}
\hline \multirow{2}{*}{$\begin{array}{l}\text { Time } \\
\text { (Min) }\end{array}$} & \multicolumn{6}{l}{ Cumulative Percent Drug Released $(\mathbf{n}=3)$} & Mean \pm S.D. & \\
\cline { 2 - 6 } $\mathbf{0}$ & $0 \pm 00$ & $0 \pm 00$ & $0 \pm 00$ & $0 \pm 00$ & $0 \pm 00$ \\
$\mathbf{5}$ & $3.64 \pm 0.014$ & $2.29 \pm 1.14$ & $1.18 \pm 2.25$ & $1.97 \pm 0.047$ & $5.69 \pm 0.65$ \\
$\mathbf{1 0}$ & $5.14 \pm 2.048$ & $5.28 \pm 1.48$ & $3.33 \pm 10.845$ & $3.47 \pm 0.065$ & $20.97 \pm 1.58$ \\
$\mathbf{1 5}$ & $13.22 \pm 0.07$ & $14.65 \pm 0.068$ & $11.11 \pm 0.98$ & $12.91 \pm 0.42$ & $39.02 \pm 1.98$ \\
$\mathbf{2 0}$ & $28.54 \pm 0.04$ & $25.64 \pm 2.46$ & $14.02 \pm 1.54$ & $18.19 \pm 0.09$ & $48.75 \pm 0.028$ \\
$\mathbf{2 5}$ & $46.47 \pm 0.06$ & $47.94 \pm 1.37$ & $25.13 \pm 1.005$ & $30.69 \pm 0.12$ & $61.25 \pm 0.87$ \\
$\mathbf{3 0}$ & $59.38 \pm 0.07$ & $51.87 \pm 2.02$ & $34.083 \pm 2.94$ & $50.13 \pm 1.57$ & $77.36 \pm 2.35$ \\
\hline
\end{tabular}

\begin{tabular}{lllll}
\hline \multirow{2}{*}{$\begin{array}{l}\text { Time } \\
\text { (Min) }\end{array}$} & \multicolumn{4}{l}{ Cumulative Percent Drug } \\
\cline { 2 - 5 } & F-6 & F-7 & F-8 & F-9 \\
\hline $\mathbf{0}$ & $0 \pm 00$ & $0 \pm 00$ & $0 \pm 00$ & $0 \pm 00$ \\
$\mathbf{5}$ & $3.16 \pm 1.0047$ & $2.34 \pm 2.015$ & $1.36 \pm 0.54$ & $0.972 \pm 2.47$ \\
$\mathbf{1 0}$ & $6.52 \pm 2.05$ & $4.25 \pm 3.035$ & $3.069 \pm 0.03$ & $3.069 \pm 1.784$ \\
\hline
\end{tabular}




\begin{tabular}{lllll}
\hline $\mathbf{1 5}$ & $15.08 \pm 1.024$ & $13.29 \pm 0.14$ & $10.69 \pm 0.64$ & $10.97 \pm 1.894$ \\
$\mathbf{2 0}$ & $33.47 \pm 1.001$ & $22.17 \pm 0.068$ & $16.8 \pm 1.58$ & $15.41 \pm 1.465$ \\
$\mathbf{2 5}$ & $52.91 \pm 0.047$ & $36.87 \pm 0.005$ & $23.74 \pm 3.65$ & $22.36 \pm 1.65$ \\
$\mathbf{3 0}$ & $64.37 \pm 0.146$ & $52.67 \pm 0.05$ & $33.47 \pm 1.84$ & $30.69 \pm 1.68$ \\
\hline
\end{tabular}

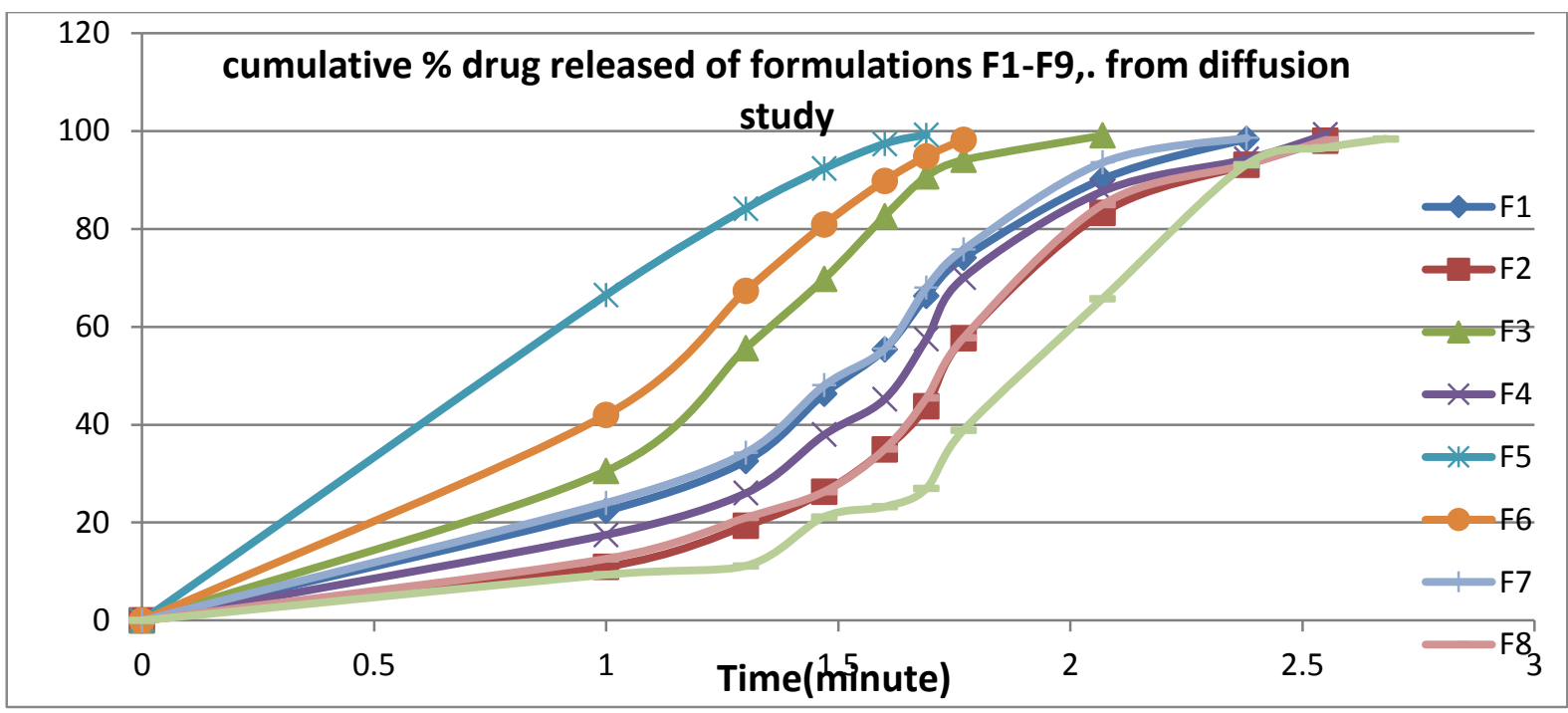

Figure 11: Plot of ex vivo permeation of Vildagliptinfrom the films formulation F1-F9

Drug ex-vivo drug permeation, it was found that the formulation $\mathrm{F}$ and $\mathrm{F}$ showed better drug permeation of $65.27 \pm 0.146 \%$ and $61.48 \pm 0.07 \%$ in 30 min respectively, when compared to other formulation as shown in table 32. But formulation F5 shows best result for drug permeation of $72.36 \pm 2.35 \%$ hence selected for stability study. The percentage amount of drug permeated was plotted against time to obtain permeation profile as shown in figure 13. It was observed that film formulation took longer time probably due to lower content of film forming polymers shows minimum drug release due to water insoluble contents of the formulation. Thus from the study it was cleared that the insoluble polymer decreases the drug release rate.

\section{Stability studies:}

The results of appearance, percent moisture loss, drug content, in-vitro disintegration time and in-vitro dissolution study of formulation F5 at 1, 2, and 3 months are shown below.

Table 24: Stability data of formulation F-5 at $40^{\circ} \mathrm{C} / 75 \% \mathrm{RH}$

\begin{tabular}{lllll}
\hline Evaluated Parameters & Initial & After 1 month & $\begin{array}{l}\text { After 2 } \\
\text { month }\end{array}$ & After 3 month \\
\hline Appearance & White, acceptable & White acceptable & $238 \pm 5.36$ & White, acceptable \\
Folding endurance & $249 \pm 5.36$ & $240 \pm 5.36$ & 15 & $237 \pm 5.36$ \\
$\begin{array}{l}\text { In-vitro disintegration time } \\
\text { (sec) }\end{array}$ & 15 & $99.63 \pm 0.364$ & 15 & \\
$\begin{array}{l}\text { Drug content (\%) } \pm \text { S.D. } \\
\text { Cumulative \% drug released }\end{array}$ & $99.69 \pm 0.364$ & $99.65 \pm 0.364$ & 99.09 & $99.59 \pm 0.364$ \\
\hline
\end{tabular}


From the result it was cleared that the film formulation F5 shows stability at the end of 3 month of study also there was no change in the physical appearance of the FDF and due to presence of $75 \% \mathrm{RH}$ there was increase in water absorption and hence increase in percent moisture loss was observed. Increase in moisture directly affects on the folding endurance of the formulation as shown in table 33. From the above result it was shown that the in vitro disintegration time, drug content and cumulative $\%$ drug release were unaffected by accelerated conditions. The results indicate that the samples were stable for 3 months.

\section{SUMMARY}

In the present work, fast dissolving films of Vildagliptin were prepared by solvent casting method using disintegrants such as HPMC, Maltodextrin and PEO.In the present dissertation an attempt was made to enhance bioavailability and increase dissolving time. The main objective of the study was to formulate and evaluate mouth-dissolving film containing Vildagliptin.

\section{From the findings obtained}

FT-IR study revealed that there is no chemical interaction between Vildagliptin and the excipients used in the study.

- The DSC thermogram of Vildagliptin with other excipients does not show profound shift in peaks which indicates compatibility.

- The prepared film containing Vildagliptin was clear and colourless. The scanning electron photomicrograph of the film at $1000 \mathrm{X}$ magnification showed smooth surface with some little pores and without any scratches or transverse striation

Formulated films gives satisfactorily result of various physico-chemical evaluation of films like physical appearance and in vitro disintegration time, and thickness of film, weight variation, tensile strength, percent elongation, folding endurance, content uniformity, and surface $\mathrm{pH}$, dissolving time, percent moisture loss, in vitro dissolving time and in vitro dissolution studies. All the films were evaluated for weight variation and thickness showed satisfactory results. Tensile strength, percentage elongation and folding endurance of the films were increased with increase in the concentration of polymer due to increase in the elasticity nature of the polymer. Mouth dissolving time and disintegration time of the films were increased with increase in the concentration of the polymer, as more fluid is required to wet the film in the mouth. Content uniformity study showed that the drug is uniformly distributed in the film. Formulation F5 shows best result for in vitro drug release due To high polymer concentration which increases the dissolution rate also act as a taste masking agent. Present study reveals that all the formulated 
films showed satisfactory film parameters. It can be concluded that, Mouth dissolving filmcontaining Vildagliptin can be prepared by casting method. \% w/v of PEO film exhibited required tensile strength, folding endurance and percentage elongation.

$>\quad$ All the prepared formulations follows first order kinetics.

$>\quad$ Short-term stability studies of promising formulation indicated that there is no significant change in drug content and in vitro dispersion time.

From the present investigation it can be concluded that mouth dissolving film formulation can be a potential novel drug dosage form for pediatric, geriatric and also for general population. Stability studies show that F5 formulation is stable up to 3 months.

\section{CONCLUSION}

The conclusions drawn from present research work are summarized as follows:

HPMC E-15 was found useful to prepare fast dissolving buccal films of Vildagliptin. Amount of film forming polymer affect film properties. The in-vitro dissolution time was very less in F5 formulation. From ex vivo permeation study formulation F5 was found the best formulation. The f5 film was found to be stable for 3 months.

So lastly we conclude that, mouth dissolving film of Vildagliptin of HPMC E15 and PEO and Maltodextrin can meet the ideal requirements for fast release intra-oral devices, which can be good way to bypass the extensive hepatic first pass metabolism and increase bioavailability.

\section{Future scope}

The development of prescription drugs into oral thin films.

In addition to the drugs, several hormones and vaccines are also being formulated into oral thin films with the aim of providing improved patient compliance.

\section{ACKNOWLEDGEMENT}

Authors thankfully acknowledge Cipla Ltd. For providing the gift sample of Vildagliptin. Authors also acknowledge the Department of Pharmaceutics, Shree Santkrupa College of pharmacy, Ghogoan and Shivaji University for providing necessary facilities and equipments to carry out the research work.

\section{REFERENCES}

1. Narayana PR, Kumar MS, Reddy M, Ravishankar K., "Formulation and Evaluation of Fast Dissolving Films of Loratidine by Solvent Casting method", Pharm Innova J. $2013 ; 2(2), 31-35$. 
2. Siddeshwar SS, Dattaprasad NV, Waghmare GA, Wadghule PB, Varpe PS, "Fast Dissolving Oral Films: Easy way ofOral Delivery.”, Int J Curr Trends Pharmaceut. Res. 2014; 2(3), 483-490.

3. Venkata Anupama M, R. Shireesh Kiran, V. Uma Maheswar Rao, P. Dileep, D. Bhavani and B. Madhavi Latha, "A Review On Oral Thin Fast Dissolving Films Recent Trend Of Dosage Form For Quick Release”, Int J Pharm Bio Sci 2014; 5(4), $54-67$.

4. Bingi Manasa, Ganesh Kumar Gudas, N. Sravanthi, R. Anusha Madhuri, Y. Lavanya And C. Pranitha.: "Formulation and evaluation of mucoadhesive buccal patches of Riesperidone”. J. A chemical. Pharmacy. Research., 2010, 2(4), 866-872.

5. Apoorva Mahajan, Neha Chhabra, Geeta Aggarwal, "Formulation and Characterization of Fast Dissolving Buccal Films: A Review", Scholar Research Library, Der Pharmacia Lettre,2011,3(1):152-165.

6. Bandaru Nagajyothi, M .Kishore Babu, "Design \& Development of Glipizide Fast Dissolving Tablets Using Natural Gum Superdisintegrant”, Asian J Pharm Clin Res, 2014, 7(1),144-148.

7. Deepak Sharma, Daljit Kaur, Shivani Verma, Davinder Singh, Mandeep Singh, Gurmeet Singh, RajeevGarg, "Fast Dissolving Oral Films Technology: A Recent Trend For An Innovative OralDrug Delivery System”, India, International Journal of Drug Delivery2015; 7, 60-75.

8. (http://www.medicalnewstoday.com/articles/194180.php)

9. Pandya K, Dr. Patel R.K., Dr, Patel M.R., Dr. Patel N.M, "Fast Dissolving Films: A Novel Approach to Oral Drug Delivery”, International Journal of Pharmamedix India, 2013, 1(2), 385-397.

10. Rajni Bala, Pravin Pawar, Sushil Khanna, Sandeep Arora, "Orally Dissolving Strips: A New Approach To Oral Drug Delivery System”, International Journal Of Pharmaceutical Investigation, April 2013,3(2),67-76.

11. Pallavi C. Patil, Shrivastava S.K., Vaidehi S., Ashwini P., "Oral Fast Dissolving Drug Delivery System-A Modern Approach For Patient Compliance”, International Journal of Drug Regulatory Affairs, 2014, 2(2), 49-60

12. Y Ganesh Kumar, J Shreekanth, D. Satyavati, "Formulation, Development and Evaluation of Sustained Release Matrix Tablets of Vildagliptin-Synthetic and Natural Polymers" Asian Journal of Pharmaceutics, 2015, 9(4), S-26 to S-33 
13. Khushabu R. Patil, Dr. Tushar A. Deshmukh, Dr. Vijay R. Patil' "Development And Validation Of Hplc Method For The Simultaneous Estimation of Vildagliptin And Metformin In Bulk And Pharmaceutical Dosage Form”, World Journal Of Pharmacy and Pharmaceutical Sciences, 2015, 4(9), 1151-1162

14. Priyanka Shrestha1, Shiva Kumar Bhandari1, SM Ashraful Islam1, Md Selim Reza and Santosh Adhikari, "Design and Development of Immediate and Sustained Release Tablets of Vildagliptin" Research Journal of Pharmaceutical, Biological and Chemical Sciences, 2014, 5(4), 811-825

15. Irin Dewan, Swarnali Islamand Md. Sohel Rana, "Characterization and Compatibility Studies of Different Rate Retardant Polymer Loaded Microspheres by Solvent Evaporation Technique: In Vitro-In Vivo Study of Vildagliptin as a Model Drug”, Journal of Drug Delivery, 2015, 1-12

16. Bhingare CL, Patidar MK, Karjikar FA,Patel FA, Rathi SS, Thokal SB., "Formulation and Evaluation of Mouth Dissolving Films of Zolpidem Tartrate by Exploration of Polymer Combination”. Int J Pharm. 2013; 3(4): 716-721.

17. Mundhe Bhagyashri, Kadam Vaishali, Jadhav Suryakant, Md. Zamiruddin,Bharkad Vishvanath, "A Short Review On Fast Dissolving Oral Film": Department of Pharmaceutics, Indira College of Pharmacy, Vishnupuri, Nanded, India World Journal Of Pharmacy And Pharmaceutical Sciences2014, 3(3): 463-475 